CHAPTER 6:

\title{
Teaching with and about information and communications technologies
}

\section{Chapter highlights}

On average across countries, most teachers tended to have experience and familiarity with information and communications technology (ICT).

- More than two thirds of teachers on average had at least five years of experience with the use of ICT during lessons or with their preparation. (Table 6.1)

- While ICT use was quite widespread among teachers in general, more frequent use when teaching was only reported by less than half of the teachers, with considerable variation across participating countries. (Table 6.1)

Most teachers tended to recognize the value of ICT use for teaching and were confident about using this technology.

- While majorities among teachers across countries expressed confidence when undertaking a large number of different ICT-related tasks, they lacked confidence regarding the use of online discussions, online collaboration, and the use of learning management systems. (Table 6.2)

- Older teachers felt less confident in using ICT (Table 6.3) and teachers who used ICT more frequently for teaching were more confident about using ICT. (Table 6.7)

- Large majorities among teachers endorsed the advantages of ICT use for student learning (Table 6.4), but there were also considerable proportions of teachers mindful of negative effects. (Table 6.5)

- In most countries, teachers with higher levels of endorsement of positive outcomes when using ICT for teaching and those who reported daily ICT use for teaching were less concerned about its potential negative effects. (Table 6.6)

There were considerable differences across countries in the availability of ICT at schools, the extent of teacher collaboration, and conditions for professional learning.

- ICILS 2018 school and teacher data show large differences in the availability and appropriateness of ICT resources across countries. (Table 6.8, Table 6.9, and Table 6.10)

- Majorities among teachers perceived collaboration between teachers (Table 6.11) and those who reported a greater extent of collaboration also perceived higher levels of ICT availability at their schools. (Table 6.12)

- Teachers who used ICT more frequently in class were also more positive about teacher collaboration and ICT resources at school. (Table 6.13)

- Teacher and school-level reports suggest large differences between countries in the expectations and requirements with regard to teacher qualifications for ICT use as well as the participation in professional learning activities. (Table 6.14 and Table 6.15) 
Teachers' placed some or strong emphasis on developing skills related to computer and information literacy and computational thinking.

- There was considerable variation in teacher emphasis across different subject areas. (Table 6.16 and Table 6.18)

- Teachers' confidence in using ICT, positive perceptions of pedagogical ICT use, and positive perceptions of teacher collaboration were positively associated with teacher emphasis on student learning of computer and information literacy and coding-related tasks. (Table 6.17 and Table 6.19)

Teachers' use of ICT in classrooms was still limited and depended on complexity of tasks and applications.

- Teachers tended to report higher levels of use for general utility tools than for digital learning tools. (Table 6.20 and Table 6.21)

- Teachers' use of ICT for student activities and teaching practices varies both across the different types of activities/practices as well as considerably across countries. (Table 6.22 and Table 6.23) 


\section{Introduction}

The International Computer and Information Literacy Study (ICILS) 2018 contextual framework (Fraillon et al. 2019) assumes that computer and information literacy (CIL) and computational thinking (CT) are influenced by context factors that are either antecedents (e.g., school resources) or process-related (e.g., teaching practices) and can be located at different levels including in the wider community, schools and classrooms, home and peer contexts, and the individual student level. Further details of this conceptual model are provided in Chapter 1. In this chapter we will focus on antecedent and process-related contextual variables that are located at the level of schools and classrooms.

Analyses of students' acquisition of CIL and CT need to acknowledge the key role that schools and classrooms play, and in this context it is interesting to note that results from a meta-analysis highlighted the positive impact of the use of information and communications technology (ICT) on classroom achievement (Tamin et al. 2011). In recent decades there has been a considerable increase in an educational policy focus on providing schools and teachers with ICT for use in education. However, results from cross-national studies have repeatedly illustrated that there are considerable differences across countries, across different subject areas, and across schools within countries, as well as between different subgroups of teachers, in particular related to age (Fraillon et al. 2014; Kozma 2003; Law et al. 2008). Research has also emphasized the importance of system and school factors in supporting teachers' pedagogical use of ICT (Eickelmann 2011; Gerick et al. 2017).

In this chapter we report the results of analyses related to teaching with and about ICT at schools across participating countries. It is based on data derived from the teacher, school principal, and ICT coordinator questionnaires, and addresses Research Question 2 related to CIL and CT: What aspects of schools and countries are related to students' CIL/CT? To this end, the chapter reviews variation in approaches to and variation in the use and availability of ICT across different national contexts. It also focuses on teachers' familiarity with ICT, their views regarding its use for teaching and learning, and the extent to which it is used in classrooms. Furthermore, it reviews the emphasis teachers place on developing CIL and CT across different subject areas and their relationship with the actual use of ICT in lessons.

The ICILS teacher survey gathered data from all teachers at sampled schools who taught at the target grade in each country (typically grade 8). Samples of 15 teachers were selected at random in each participating school and invited to participate in the survey. In schools with 20 or fewer teachers, all of them were invited to complete the questionnaire.

To capture teachers' ICT-related perceptions in their in-class teaching, ICILS 2018 asked teachers some questions with regard to a specific reference class taught at the target grade. Teachers were asked to identify the reference class as the first class they taught on the Tuesday (or on the next day in the week they were teaching if they did not have classes on Tuesday) following the last weekend. A large number of questions were then asked about that particular reference class.

ICILS 2018 also collected data at the school level using two instruments. School principals completed a 10-minute questionnaire providing information about school characteristics, school approaches to CIL and CT learning, and incorporating ICT into teaching and learning. Schools were also asked to name an ICT coordinator, this could be either a formal or informal position or be another specifically nominated staff member with knowledge about ICT-related issues at school. These staff members completed a 10-minute questionnaire providing information about ICT resources, and technical and pedagogical support for ICT use for teaching and learning at school. 
Data from both of these instruments were reported at the level of students by matching school data to individual learners. In line with common practice in other IEA studies, this was done to provide a better picture of school contexts for the "average student" in each country as schools with few students would otherwise have the same weight as larger schools with much higher numbers of students.

The ICILS 2018 teacher questionnaire was used to measure a number of constructs that underpin scales and items presented in this chapter. We used item response theory (IRT) scaling (Masters and Wright 1997; Rasch 1960) to derive the scales presented in this chapter, which were set to a metric with a mean of 50 and a standard deviation of 10, with equally weighted national data from those countries that had met the IEA sampling requirements for the teacher survey. All scales are described in item maps contained in Appendix F of this report. The maps relate scale scores to expected item responses under the ICILS scaling model (also illustrated in Figure F.1, Appendix F). Greater detail regarding the scaling procedures for questionnaire items will be provided in the ICILS 2018 technical report (Fraillon et al. 2020).

In five countries the teacher participation rates did not meet the IEA requirements for sampling participation. Therefore, in adherence to IEA standards for reporting, teacher questionnaire results from this relatively large group of countries are reported in an extra section of the respective reporting tables and not included in comparisons with those from other countries. Readers are advised to interpret teacher data from countries not meeting the sample participation requirements with due caution.

\section{Teachers' familiarity with and views of ICT}

\section{Teachers' experience and use}

Prior research has indicated relationships between experiences of teaching staff with ICT, the extent of its use, and their attitudes toward digital technologies as tools for teaching and learning (see Drossel et al. 2017; Fraillon et al. 2014; Nikolopolou and Gialamas 2016). The ICILS 2018 teacher questionnaire asked teachers about their (approximate) years of experience ("never," "less than two years," "between two and five years," or "more than five years") with using ICT for teaching purposes during lessons as well as when preparing lessons. Given that majorities of teachers across all countries were found in the highest categories of years of experience, we present the results in percentages of teachers reporting to have five or more years of experience.

Furthermore, teachers were asked to rate their frequency ("never," "less than once a month," "at least once a month but not weekly," "at least once a week but not every day," or "every day") of using ICT at school when teaching, at school for other work-related purposes, outside school for work-related purposes, and outside school for non-work-related purposes. Results are presented as percentages of teachers who reported using ICT every day.

On average across participating countries, about two thirds of teachers reported having five or more years of experience with the use of ICT during lessons, while an even higher percentage (72\%) reported having a similar length of experience with the use of ICT for preparing lessons (Table 6.1). The highest percentages of teachers indicating long experience for both activities were recorded in Denmark, Portugal, and the benchmarking participant Moscow (Russian Federation), while the lowest percentages were reported in Italy, Kazakhstan, and the benchmarking participant North Rhine-Westphalia (Germany). 


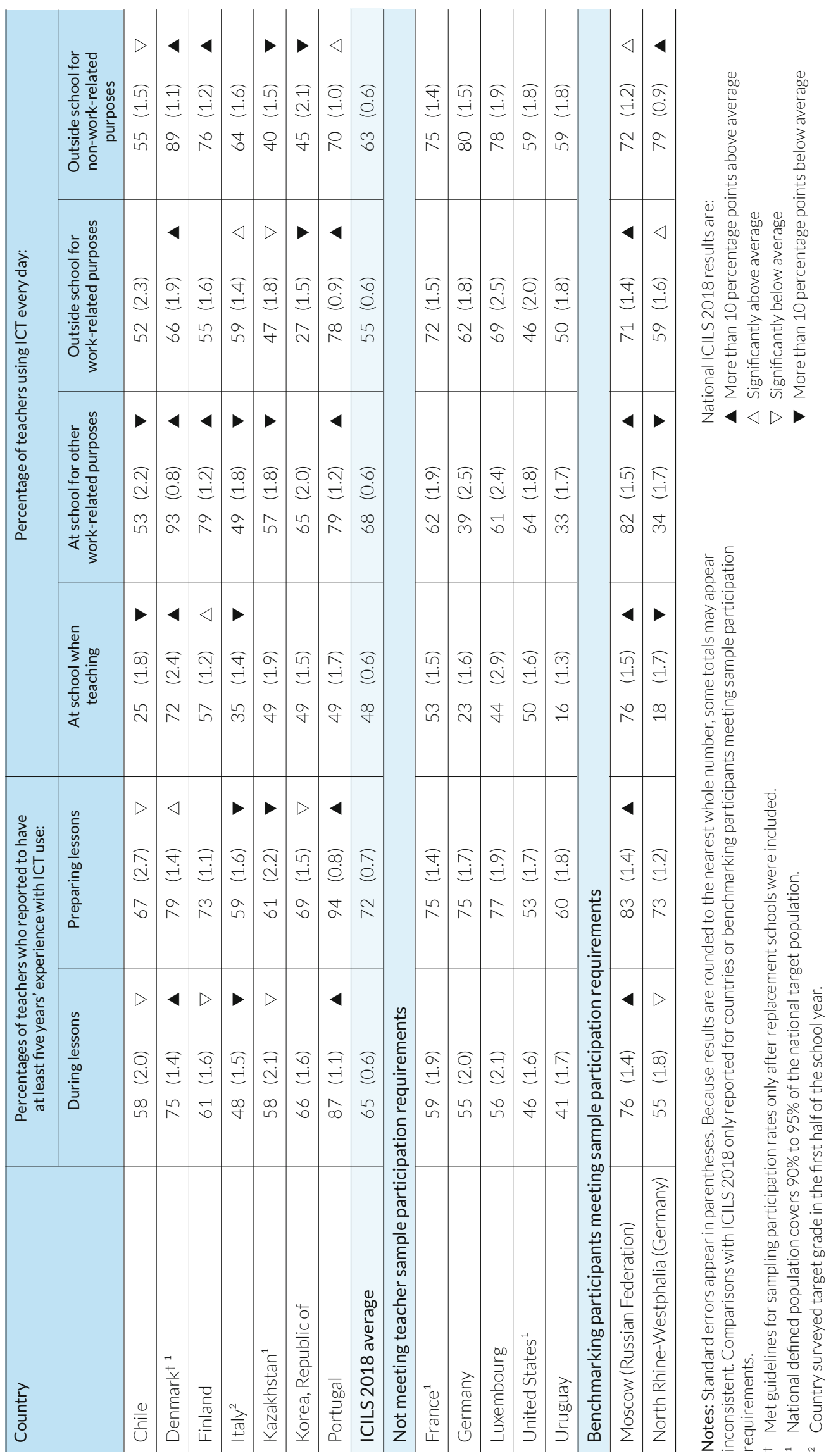




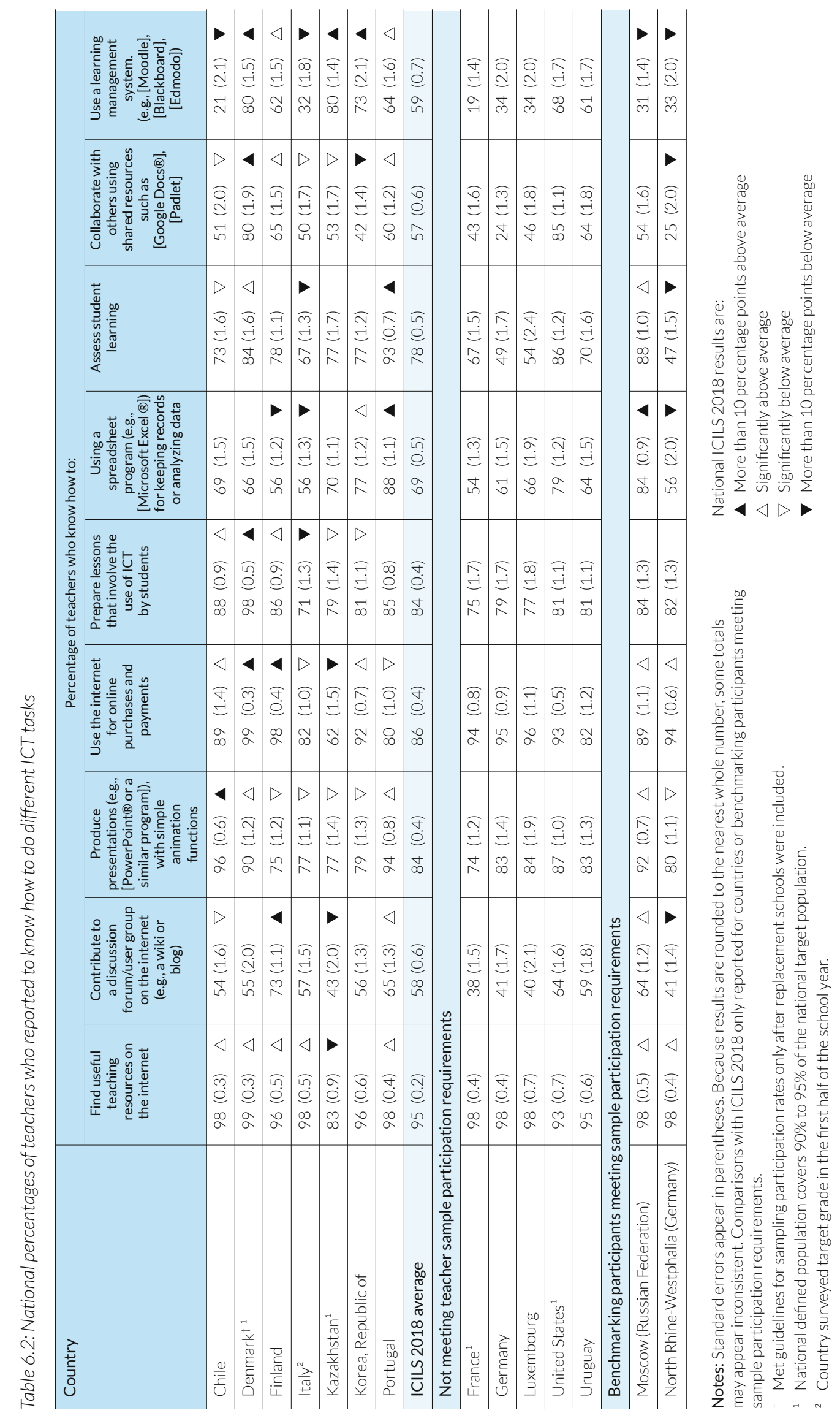


On average across countries, two thirds of teachers used ICT daily for other work-related purposes at school while less than half of the teachers reported daily use of ICT when teaching. The highest percentages of ICT for teaching were found among teachers in Denmark, Finland, and Moscow (Russian Federation), while the lowest percentages of this type of ICT use were recorded in Chile, Italy, and North Rhine-Westphalia (Germany). In most countries, more than half of the teachers reported daily use of ICT for work-related purposes at school; however, in the benchmarking participant North Rhine-Westphalia (Germany) we found very low percentages, with only every fifth teacher reporting use of ICT for these purposes.

Percentages of at least weekly ICT use for work-related purposes tended to be above 50 percent in most countries; however, among teachers in Korea only about a quarter fell into this category. Using ICT at least weekly for non-work-related purposes was reported by most teachers across countries; however, somewhat lower percentages were recorded in Kazakhstan and Korea.

\section{Teachers' ICT-related self-efficacy}

Bandura's (1997) concept of self-efficacy refers to individuals' belief in their capacities to organize and execute a course of action to obtain specific outcomes, which in turn influence their choices with regard to undertaking tasks, the efforts with which they conduct them, and their extent of perseveration. There is evidence that teachers' sense of self-efficacy regarding the use of ICT influences its use by teachers in the classroom (Fraillon et al. 2014; Hatlevik 2017; Hatlevik and Hatlevik 2018; Law et al. 2008; Nikolopolou and Gialamas 2016). ICILS 2018 asked teachers to rate how well they can do a range of different ICT tasks ("I know how to do this," "I haven't done this but I could find out how," "I do not think I could do this"). Results are presented as the percentages of teachers who reported to know how to do each of these tasks (Table 6.2).

On average across participating countries, we found that more than three quarters of teachers believed they knew how to "find useful teaching resources on the internet" (95\%), "produce presentations (e.g., [PowerPoint $\AA$ or a similar program]), with simple animation functions" (84\%), "use the internet for online purchases and payments" (86\%), "prepare lessons that involve the use of ICT by students" (86\%), and "assess student learning" (78\%). Somewhat more than two thirds expressed confidence in "using a spreadsheet program for keeping records or analyzing data" (69\%). We observed the lowest levels of confidence (somewhat more than half of the teachers) for "contributing to a discussion forum/user group on the internet (e.g., a wiki or blog)" (58\%), "collaborating with others using shared resources such as Google Docs $®$ or Padlet" (57\%), and "using a learning management system" (59\%). Notably lower levels of confidence were recorded in some individual countries, such as for the use of a learning management system in Chile (21\%) or collaboration with others using shared resources in North Rhine-Westphalia (Germany) (25\%).

All nine items were used to derive an IRT scale reflecting teachers ICT self-efficacy, where higher scales reflect higher levels of self-efficacy. The scale had satisfactory reliability (an average Cronbach's alpha of 0.80) across participating countries (Figure F.17 in Appendix F contains the corresponding item map showing how scale scores relate to item responses). The highest levels of teachers' ICT self-efficacy were observed in Denmark and Portugal, while teachers in Italy, Kazakhstan, and North Rhine-Westphalia (Germany) had the lowest levels of teacher selfefficacy (Table 6.3). 

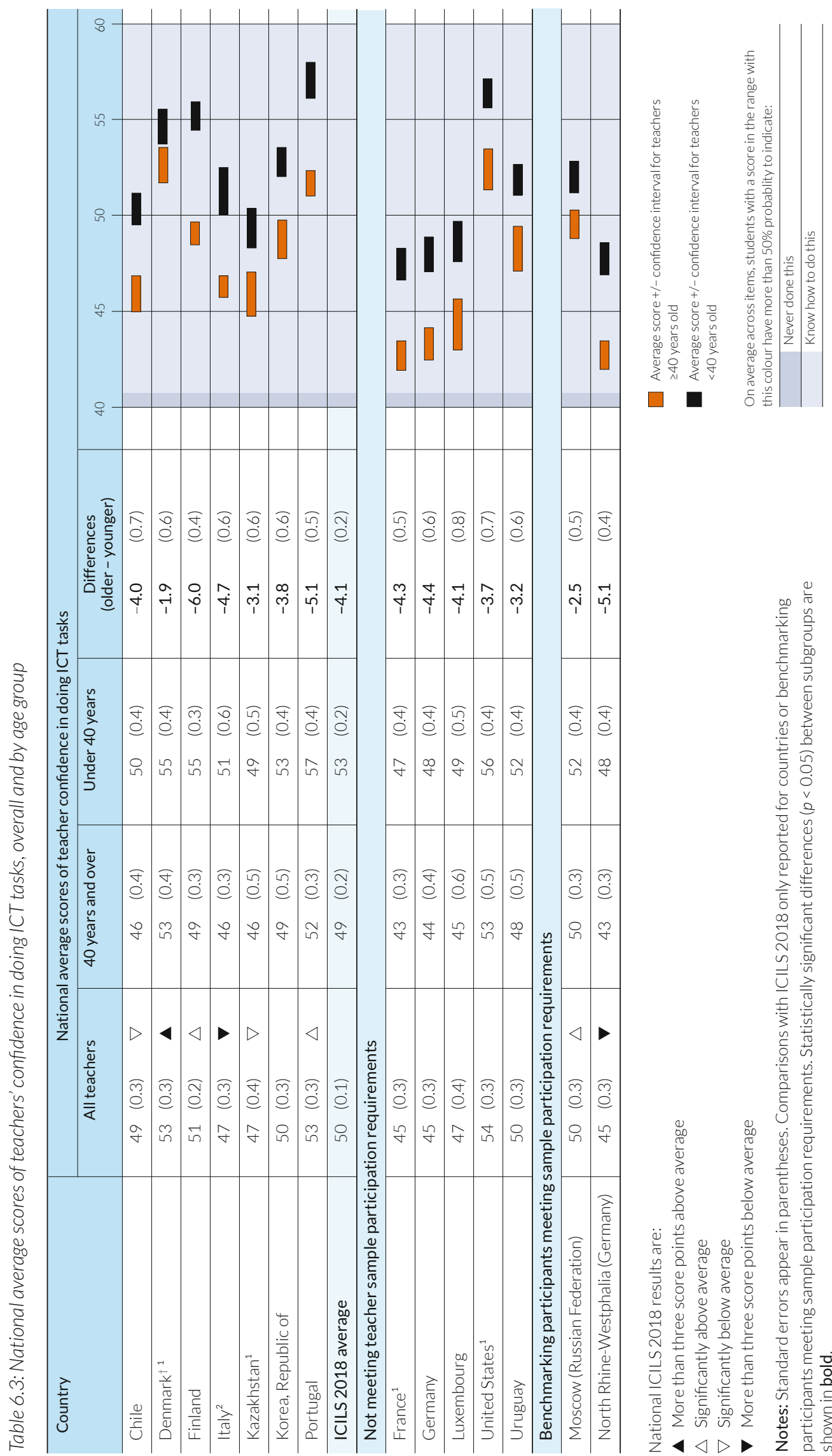
To review differences in ICT-related self-efficacy between younger and older teachers, we distinguished between teachers who were 40 years of age and older and those who were younger than 40 years at the time of the survey. In all participating ICILS 2018 countries we observed significantly higher scale scores for teachers who were younger than 40 years compared with those who were 40 years of age and older, with an average scale score difference of about four points (more than an international standard deviation), ranging from a two-point difference in Denmark to a six-point difference in Finland. These results confirm earlier findings (see, for example, Fraillon et al. 2014) about the association between age and teacher ICT-related selfefficacy, as well as illustrating notable differences in this association across countries.

\section{Teachers' views of ICT for teaching and learning}

Positive teacher attitudes toward the use of ICT for teaching and learning are regarded as important key factors for the implementation of digital technologies for teaching and learning at schools (Lawrence and Tar 2018; Tondeur et al. 2017). European survey data from 2011 illustrated that across the region teachers tended to express positive attitudes toward the use of ICT in the classroom (Wastiau et al. 2013) and ICILS 2013 data also revealed that across participating countries there was a widespread recognition of positive benefits from using ICT in teaching (Fraillon et al. 2014).

ICILS 2018 continued to gather teachers' views on using ICT for teaching and learning by asking them about their level of agreement or disagreement ("strongly agree," "agree," "disagree," or "strongly disagree") with a number of statements. Seven of these statements related to positive outcomes of using ICT in education that were helping with student learning, while another six statements referred to outcomes that reflected potential impediments of learning. Results are presented in the following two tables as percentages of teachers who agreed or strongly agreed with each of these statements.

Across participating countries, large majorities among teachers agreed with statements about positive outcomes of using ICT in teaching and learning (Table 6.4). The highest proportions of agreement (above 85\%) were recorded for the statements "helps students develop greater interest in learning," "enables students to access better sources of information," and "helps students to work at a level appropriate to their learning needs." The lowest proportions on average (below 75\%) were observed for the statements "improves academic performance of students" and "helps students develop skills in planning and self-regulation of their work." The remaining two statements ("helps students develop problem-solving skills" and "enables students to collaborate more effectively") were endorsed by almost 80 percent across countries.

When comparing results across countries, there was relatively little variation for the three items that on average had the highest levels of endorsement. However, the statement relating to the improvement of academic performance received varying levels of agreement by teachers across countries. While two thirds or more of teachers expressed agreement with this statement in Chile, Denmark, Kazakhstan, and Portugal, less than half of the teachers endorsed this notion in Finland and North Rhine-Westphalia (Germany).

On average across participating countries, only two of the statements about negative outcomes of using ICT in teaching and learning, expressing that ICT use results in "students copying material from internet sources" (71\%) and in "poorer written expression among students" (52\%), were endorsed by more than half of the teachers (Table 6.5). In most countries, less than a quarter of surveyed teachers endorsed the notion that using ICT "impedes concept formation by students;" however, this was seen as a problem by more than two thirds of teachers in Kazakhstan. Less than half of the teachers across ICILS 2018 countries agreed that ICT use "distracts students from learning" (37\%), "results in poorer calculation and estimation skills among students" (41\%), or "limits the amount of personal communication among students" (46\%). 


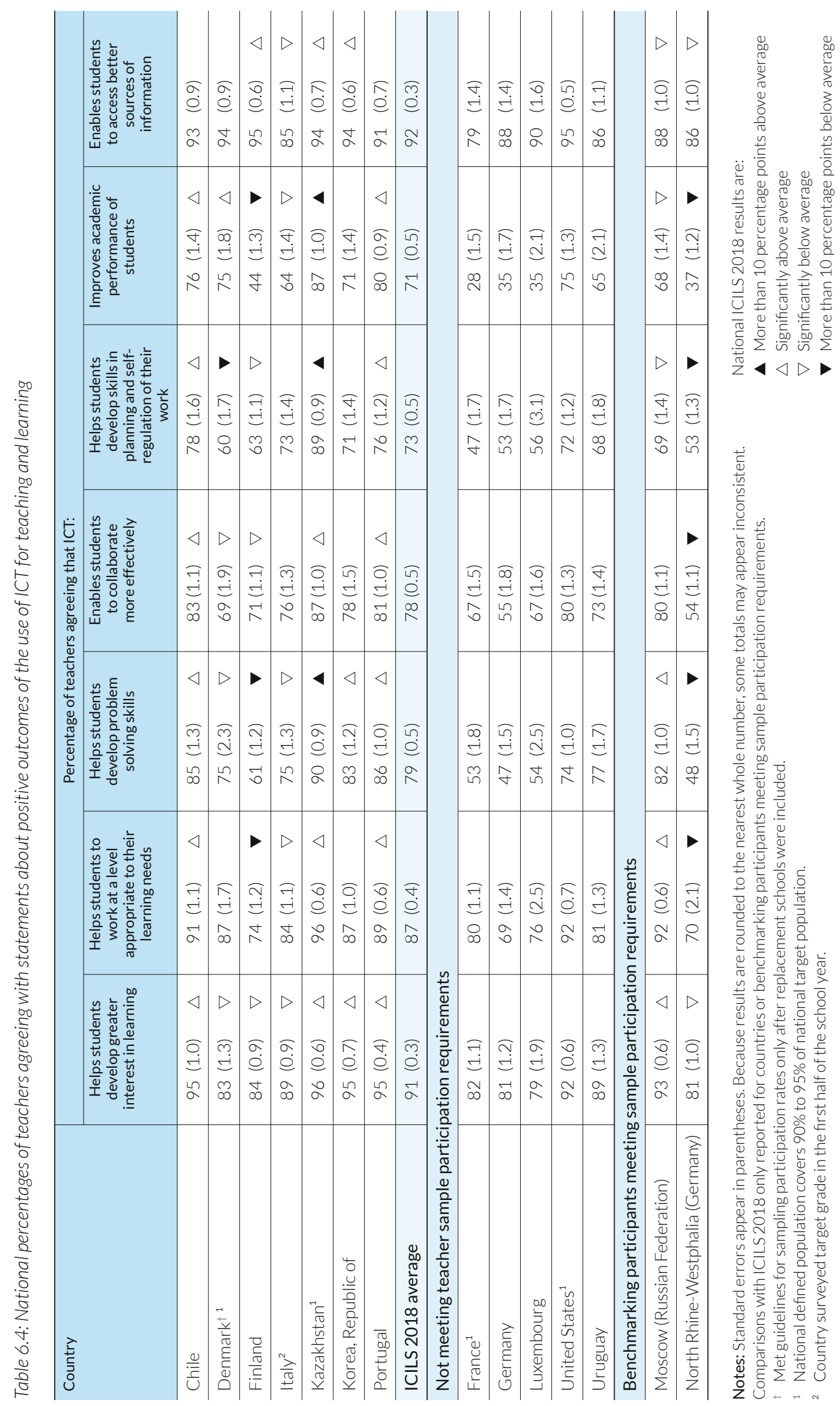




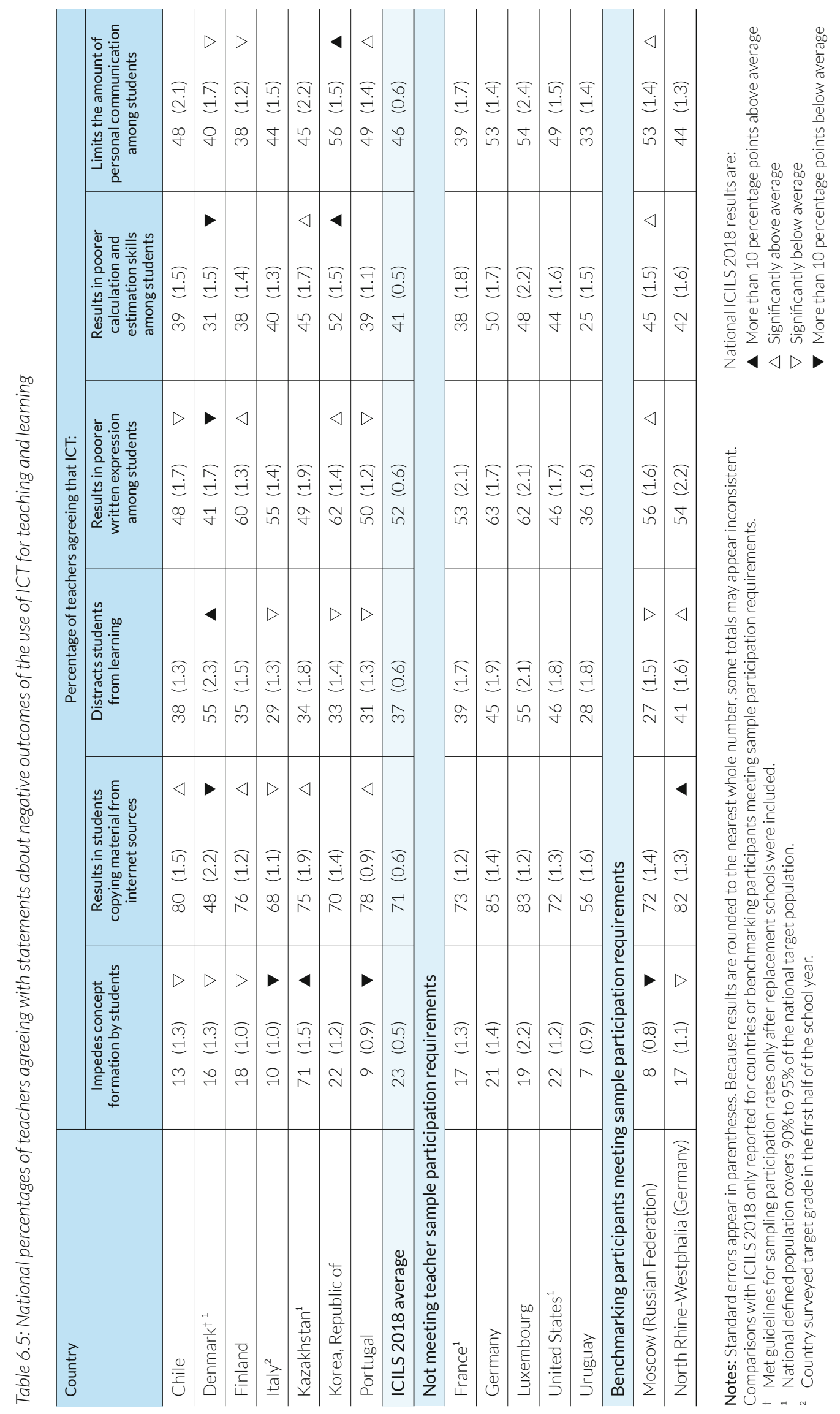


Across participating countries there was some notable variation in teachers' agreement with these statements about negative effects of using ICT. In Kazakhstan and Korea, relatively high levels of endorsement were recorded, while Danish teachers were least likely to agree with notions of negative outcomes. However, these patterns were also not entirely consistent; for example, more than half of the teachers in Denmark agreed that ICT use may distract students, while in most other countries lower proportions among teachers were of this view.

The items related to effects of ICT use for teaching and learning were used to derive two IRT scales, one indicating perceptions of positive outcomes when using ICT in teaching and learning (based on the seven items shown in Table 6.4) and the other reflecting perceptions of negative outcomes when using ICT in teaching and learning (based on the six items shown in Table 6.5). Both scales had satisfactory reliabilities (Cronbach alpha coefficients on average across ICILS 2018 countries were 0.84 and 0.80 respectively). Higher scale scores (set to a metric where 50 is the average ICILS 2018 scale score and 10 the standard deviation for the combined pooled data set) reflect higher levels of agreement with the respective statements used for measurement (see Figures F.18 and F.19 in Appendix F for item maps linking scales scores to expected item responses).

When comparing average scale scores for both scales across participating ICILS 2018 countries (Table 6.6), the results show that there is relatively more variation across countries for teachers' perceptions of positive outcomes than for teachers' perceptions of negative outcomes when using ICT for teaching and learning. The highest endorsements of positive outcomes when using ICT in teaching and learning were observed in Chile and Kazakhstan, while notably lower scores on this scale were recorded in Finland and North Rhine-Westphalia (Germany). For the scale measuring teachers' perceptions of negative outcomes when using ICT, the highest scores were found in Kazakhstan and the lowest scores in Denmark.

The correlation at the country level between average scale scores for these two scales was -0.29 , which demonstrates that there was no strong consistent pattern where countries with on average higher levels of recognition of positive outcomes also had teachers who tended to be less concerned about negative outcomes. However, the correlations within countries (see Table 6.6) show that teachers who agreed more with statements about positive consequences of ICT use were also more likely to disagree with those reflecting negative ones. On average, a moderate negative correlation (Pearson's r) of -0.36 was recorded, which was consistently negative in all participating countries except Kazakhstan, where we observed a weak (albeit statistically significant) positive correlation.

\section{Associations of teachers' use of digital technologies with their views of ICT}

ICILS 2013 results showed that teachers' views of ICT are associated with the extent to which they use it for teaching purposes (Fraillon et al. 2014, p. 210). To review the relationship between the two factors we compared average scale scores across two groups of teachers, those who used ICT for teaching on a daily basis and those who used ICT less frequently (Table 6.7).

The results show that teachers who reported a daily use of ICT for teaching had significantly higher scale scores for ICT self-efficacy and perceptions of positive outcomes when using ICT for teaching and learning. Correspondingly, daily users of ICT for teaching and learning were less likely to recognize negative consequences of using ICT. On average across participating countries, teachers who used ICT for teaching on a daily basis had scale scores of ICT self-efficacy that were four points higher than those in the comparison group (with differences ranging from two to more than five points). Differences between the two comparison groups for perceptions of positive outcomes of ICT use for teaching and learning were slightly smaller (about three points), with hardly any variation across countries. Daily users of ICT for teaching had, on average, about two points less on the scale measuring perceptions of negative outcomes when using ICT compared to other teachers (with differences varying across countries to a limited degree between one and three points). 


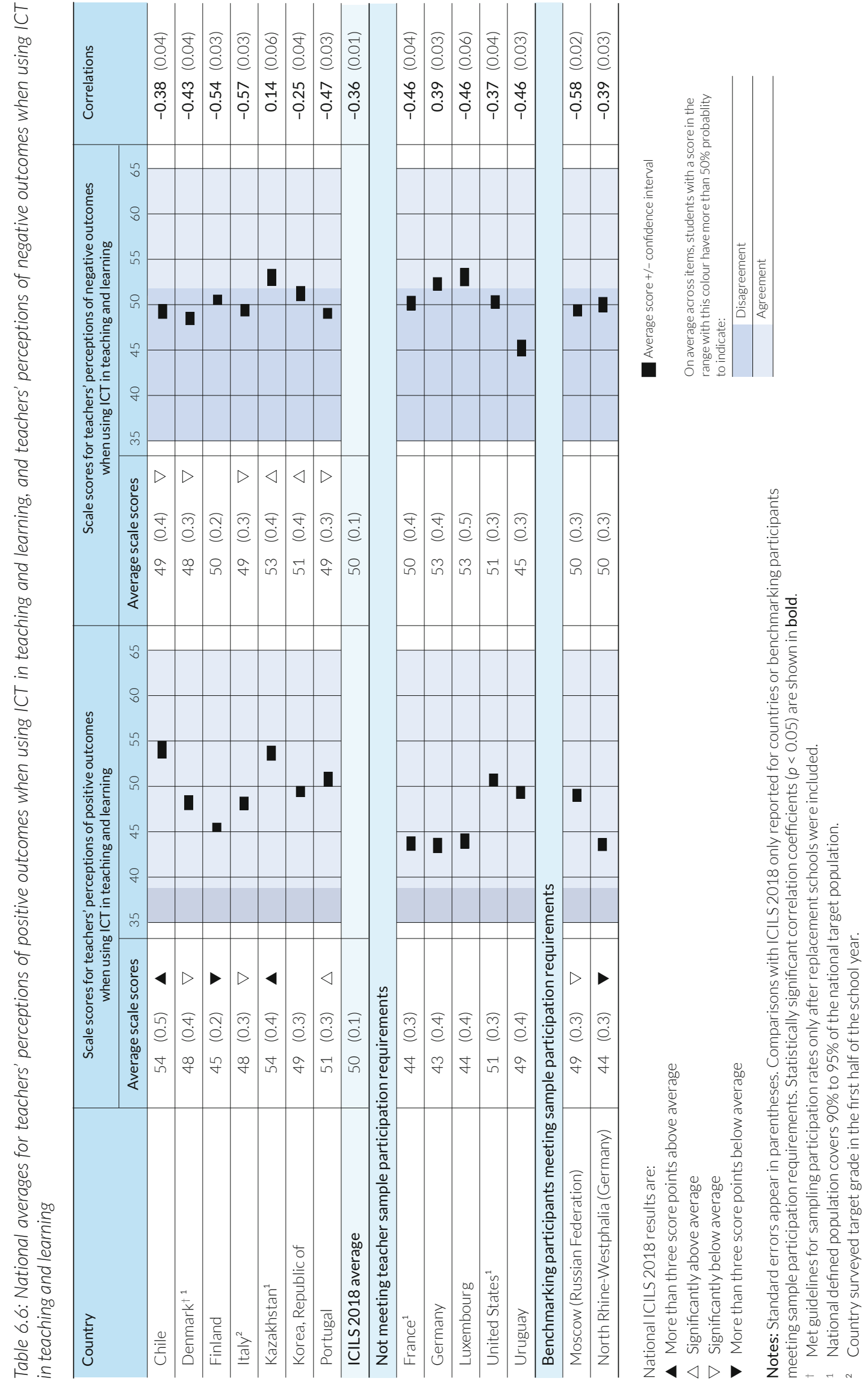




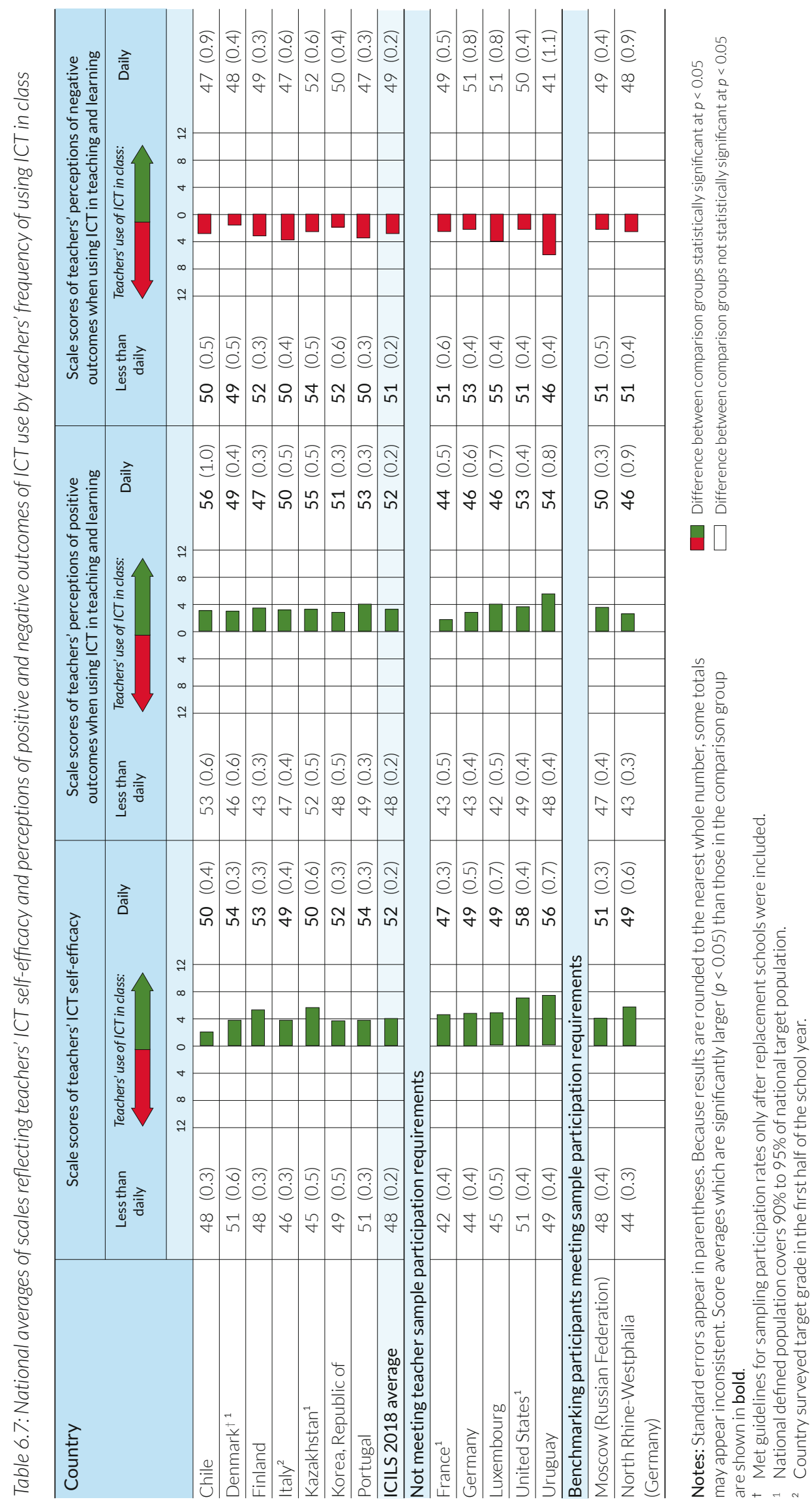




\section{Perceptions of schools' ICT learning environments}

\section{Perceptions of school resources for ICT use}

Research has suggested that school-level factors related to ICT resourcing and priorities influence both the way in which teachers use ICT for teaching and learning, and students' ICT-related learning (Fraillon et al. 2014; Gerick et al. 2017; Lawrence and Tar 2018). In this section, we will use data collected from teachers, school principals, and ICT coordinators to review perceptions of ICT learning environments at schools in participating ICILS 2018 countries.

School ICT coordinators were asked about the extent to which they perceived that the use of ICT for teaching was hindered by different factors ("a lot," "to some extent," "very little," or "not at all"). One group of factors related to the lack of computer resources at school, while the other group of factors related to pedagogical resources. The results were reported at the level of students: that is, in percentages of students who were enrolled at schools where each of the factors was reported as a hindrance to ICT use for teaching a lot or to some extent.

Across countries, almost half of students studied at schools where insufficient bandwidth or speed (48\%), not enough computers for instruction (48\%), and lack of sufficiently powerful computers (47\%) were reported as hindrances (Table 6.8). Slightly lower proportions of students were enrolled at schools with problems maintaining ICT equipment (44\%) and not having enough computer software (38\%), while on average less than a third of students studied at schools where having too few computers with internet connections was reported as a problem.

There was considerable variation across countries in the percentages of students at schools where insufficient computer resources were viewed as a problem. While in Denmark, Korea, and Luxembourg only few students were enrolled at schools where computer resources were reported as hindrances for using ICT for teaching, this was the case for substantially higher proportions of students in Germany, Italy, Portugal, and Uruguay.

Compared to the results for computer resource hindrances, we observed generally higher proportions of students at schools where the lack of pedagogical resources was seen as a hindrance to using ICT for teaching across participating countries (Table 6.9). Almost two thirds of students studied at schools where insufficient ICT skills among teachers (65\%) and insufficient time for teachers to prepare lessons (64\%) were viewed as hindrances for using ICT for teaching. On average, half or more of surveyed students were enrolled at schools where the lack of effective professional learning resources for teachers (59\%), lack of incentives for teachers to integrate ICT in their teaching (57\%), and insufficient pedagogic support for the use of ICT (50\%) were reported as problems. Across countries, lack of an effective online learning support platform at their schools affected the relatively lowest proportion of students (44\%).

Again, we observed substantial differences across participating countries. While in Denmark, Kazakhstan, Korea, and Moscow (Russian Federation) the proportions of students at schools with a reported lack of pedagogical resources tended to be smaller across the different factors, these percentages were higher in Finland, Germany, Portugal, and Uruguay. However, it should be noted that these patterns were not always consistent across the different factors. For example, in most countries there were high proportions of students studying at schools where insufficient ICT skills and insufficient time for preparing lessons were regarded as hindering ICT use for teaching and learning.

The teacher questionnaire collected data on teacher perceptions of ICT resources at their schools by asking them about their agreement or disagreement with a number of statements ("strongly agree," "agree," "disagree," or "strongly disagree"). Seven of these items (excepting the item "ICT is considered a priority for use in teaching") were used to derive an IRT scale reflecting teachers' perceptions of the availability of ICT resources at school. The scale had satisfactory reliability across 

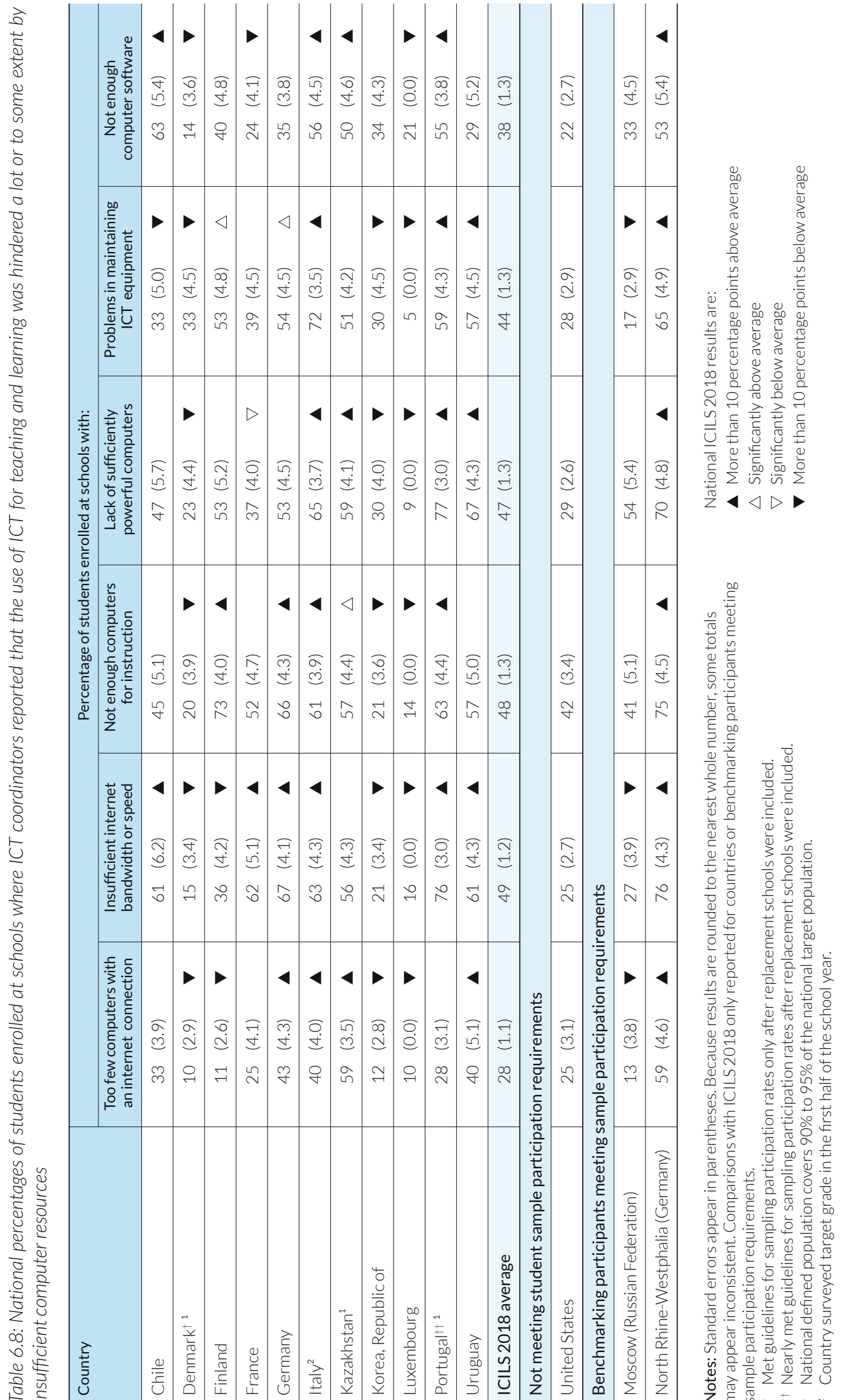


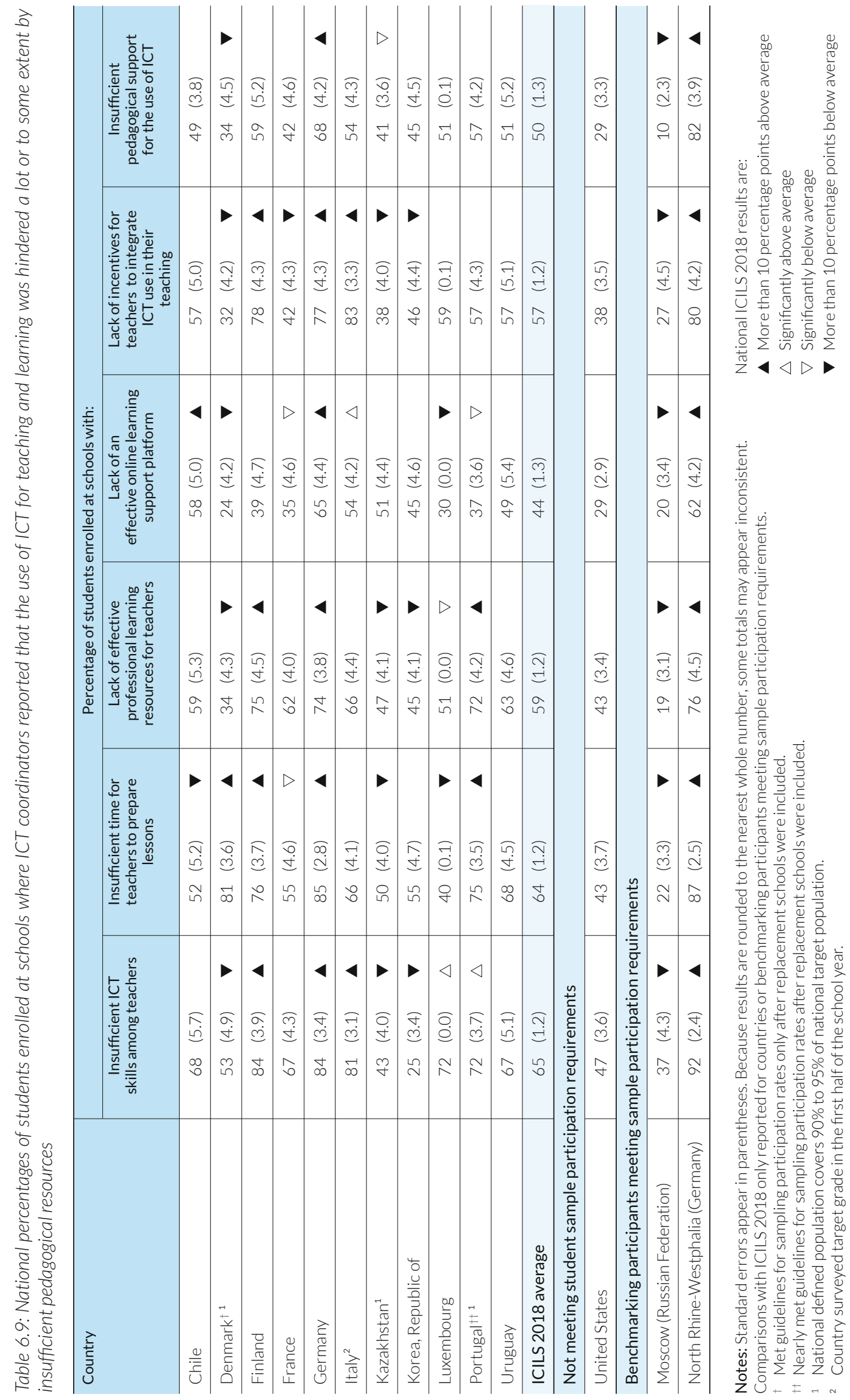


participating countries (Cronbach's alpha $=0.87$ ), and higher scores indicate perceptions of greater availability of ICT resources (see the corresponding item map in Figure F.2O in Appendix F linking scale scores to expected item responses).

The results at the item level show that typically more than 80 percent of teachers expressed agreement (incorporating "strongly agree" and "agree" responses) that ICT was considered a priority for use in teaching across participating countries, with somewhat lower proportions recorded in Italy (74\%) and considerably lower percentages found in North Rhine-Westphalia (Germany) (33\%) (Table 6.10). On average across participating countries, over half of the teachers also endorsed the statements that their school had sufficient ICT equipment (62\%), that their school's computer equipment was up-to-date (61\%), that their school had access to sufficient digital learning resources (59\%), that there was sufficient time to develop expertise in ICT (51\%), and that there was sufficient support to maintain ICT resources (55\%). Less than half of the teachers, on average across countries, agreed that there was enough time to prepare lessons incorporating ICT (41\%); however, there was some variation regarding this aspect, as two thirds or more of teachers in Kazakhstan and Moscow (Russian Federation) regarded time for this as sufficient.

Research has suggested that there are benefits of teacher collaboration with colleagues for the development of ICT self-efficacy and promoting the use of ICT for teaching purposes (see, for example, Caspersen and Raaen 2014; Drossel et al. 2017; Fraillon et al. 2014). ICILS 2018 asked teachers about their perceptions of whether and how ICT is used as part of collaborative teaching and learning at their school. ICILS 2018 asked teachers about their agreement or disagreement with five statements regarding collaboration among colleagues regarding the use of ICT ("strongly agree," "agree," "disagree," or "strongly disagree"). All five items were the basis for an IRT scale reflecting teachers' perceptions of the collaboration between teachers when using ICT. The scale had satisfactory reliability across participating countries (Cronbach's alpha $=0.86$ ) and higher scores indicate perceptions of greater collaboration between teachers (see the corresponding item map in Figure F.21 in Appendix F linking scale scores to expected item responses).

On average across participating countries, teachers tended to express agreement (incorporating "strongly agree" and "agree" responses) with statements regarding the collaborative use of ICT in teaching and learning at their schools (Table 6.11). About three-quarters agreed with the statements that they discussed with other teachers how to use ICT for teaching topics (75\%) and that they shared ICT-based resources with other school teachers (74\%). Furthermore, about two thirds of teachers agreed that they worked together with other teachers on improving the use of ICT in classrooms (65\%) and that they observed how other teachers used ICT in teaching (71\%). The lowest percentages of agreement were recorded for the statement regarding collaboration with colleagues to develop ICT-based lessons; however, in most countries more than half the teachers expressed agreement (61\% on average).

There were some notable differences across countries regarding agreement with the statements related to teacher collaboration. While in Kazakhstan and Moscow (Russian Federation) very large majorities (above 80\%) agreed with all of the statements, there were particularly low proportions of agreement in North Rhine-Westphalia (Germany) with the statements regarding working together with colleagues on improvements in the use of ICT in lessons (36\%) and collaboration to develop ICT-based sessions (30\%).

When comparing national average scale scores for teachers' perceptions of the availability of ICT resources at school and teachers' perceptions of collaboration between teachers when using ICT, we observed considerable variation across countries for both scales (Table 6.12). When looking at the distribution of national averages across countries, it becomes evident that in countries where teachers perceived greater levels of availability of ICT resources, there were also 


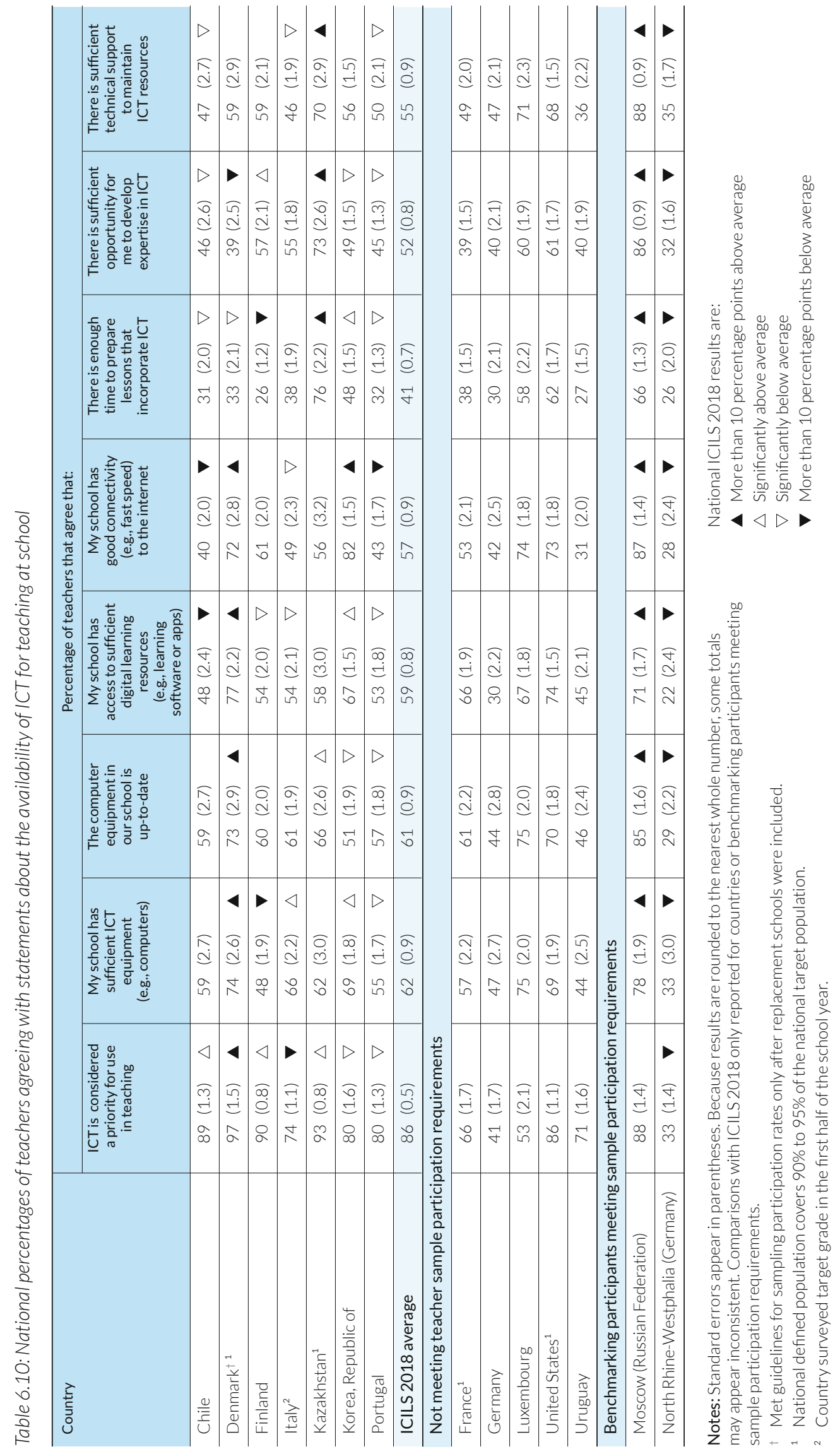


Table 6.11: National percentages of teachers agreeing with statements about the collaborative use of ICT in teaching and learning

\begin{tabular}{|c|c|c|c|c|c|c|c|c|c|c|c|}
\hline \multirow{3}{*}{$\begin{array}{l}\text { Country } \\
\text { Chile }\end{array}$} & \multicolumn{11}{|c|}{ Percentage of teachers that agree that: } \\
\hline & \multicolumn{2}{|c|}{$\begin{array}{l}\text { I work together with } \\
\text { other teachers on } \\
\text { improving the use of } \\
\text { ICT in classroom } \\
\text { teaching }\end{array}$} & \multicolumn{2}{|c|}{$\begin{array}{c}\text { I collaborate with } \\
\text { colleagues to } \\
\text { develop ICT-based } \\
\text { lessons }\end{array}$} & \multicolumn{3}{|c|}{$\begin{array}{c}\text { I observe how } \\
\text { other teachers } \\
\text { use ICT in teaching }\end{array}$} & \multicolumn{2}{|c|}{$\begin{array}{l}\text { I discuss with } \\
\text { other teachers } \\
\text { how to use ICT } \\
\text { in teaching topics }\end{array}$} & \multicolumn{2}{|c|}{$\begin{array}{l}\text { I share ICT-based } \\
\text { resources with } \\
\text { other teachers in } \\
\text { in my school }\end{array}$} \\
\hline & $57(1.9)$ & $\nabla$ & $59(1.8)$ & & & $(1.2)$ & $\nabla$ & $62(1.5)$ & $\nabla$ & $69(1.4)$ & $\nabla$ \\
\hline Denmark $^{\dagger 1}$ & $63(2.2)$ & & $57(2.0)$ & $\nabla$ & 57 & (1.9) & $\nabla$ & $75(1.5)$ & & $79(1.4)$ & $\triangle$ \\
\hline Finland & $68(1.1)$ & $\triangle$ & $56(1.4)$ & $\nabla$ & 75 & $(1.2)$ & $\triangle$ & $78(1.0)$ & $\triangle$ & $56(1.0)$ & $\nabla$ \\
\hline Italy ${ }^{2}$ & 68 (1.4) & & 59 (1.8) & & 74 & $(1.3)$ & $\triangle$ & $80(1.5)$ & $\triangle$ & $73(1.5)$ & \\
\hline Kazakhstan $^{1}$ & $94 \quad(0.9)$ & $\Delta$ & $93(0.7)$ & $\Delta$ & 90 & (1.2) & $\boldsymbol{\Delta}$ & $93(0.8)$ & $\Delta$ & $93(0.9)$ & $\Delta$ \\
\hline Korea, Republic of & $50(1.6)$ & $\boldsymbol{\nabla}$ & $51(1.9)$ & $\nabla$ & 69 & $(1.3)$ & $\nabla$ & $65(1.4)$ & $\nabla$ & $66(1.5)$ & $\nabla$ \\
\hline Portugal & $55 \quad(1.3)$ & $\nabla$ & 55 (1.3) & $\nabla$ & 67 & (1.3) & $\nabla$ & $74(1.2)$ & & $82(1.0)$ & $\triangle$ \\
\hline ICILS 2018 average & $65(0.6)$ & & $61(0.6)$ & & 71 & $(0.5)$ & & $75(0.5)$ & & $74(0.5)$ & \\
\hline \multicolumn{12}{|c|}{ Not meeting teacher sample participation requirements } \\
\hline France $^{1}$ & $55(1.7)$ & & $44(1.6)$ & & 58 & $(1.4)$ & & $82(1.1)$ & & $64(1.6)$ & \\
\hline Germany & $38(1.8)$ & & $33(1.8)$ & & 54 & $(2.3)$ & & $58(2.0)$ & & $54(2.1)$ & \\
\hline Luxembourg & $47 \quad(2.1)$ & & $39(2.1)$ & & 67 & $(2.1)$ & & $81(2.0)$ & & $70(1.9)$ & \\
\hline United States $^{1}$ & $66(1.5)$ & & $59(1.8)$ & & & $(1.5)$ & & $75(1.2)$ & & $74(1.3)$ & \\
\hline Uruguay & $70(1.2)$ & & $67(1.4)$ & & 79 & $(1.4)$ & & $86(1.0)$ & & $78(1.2)$ & \\
\hline \multicolumn{12}{|c|}{ Benchmarking participants meeting sample participation requirements } \\
\hline Moscow (Russian Federation) & $82(1.3)$ & $\boldsymbol{\Delta}$ & $80(1.4)$ & $\boldsymbol{\Delta}$ & 91 & (0.8) & $\boldsymbol{\Delta}$ & $95(0.5)$ & $\Delta$ & $87(0.8)$ & $\boldsymbol{\Delta}$ \\
\hline North Rhine-Westphalia (Germany) & $36(2.4)$ & $\boldsymbol{\nabla}$ & $30(2.0)$ & $\nabla$ & 57 & $(2.0)$ & $\nabla$ & $67(1.7)$ & $\nabla$ & $61(1.9)$ & $\boldsymbol{\nabla}$ \\
\hline
\end{tabular}

Notes: Standard errors appear in parentheses. Because results are rounded to the nearest whole number, some totals may appear inconsistent. Comparisons with ICILS 2018 only reported for countries or benchmarking participants meeting sample participation requirements.

† Met guidelines for sampling participation rates only after replacement schools were included.

1 National defined population covers $90 \%$ to $95 \%$ of the national target population.

2 Country surveyed target grade in the first half of the school year.

\section{National ICILS 2018 results are:}

- More than 10 percentage points above average

$\triangle$ Significantly above average

$\nabla$ Significantly below average

$\boldsymbol{\nabla}$ More than 10 percentage points below average

teacher perceptions of greater collaboration between colleagues on the use of ICT at schools. The country-level correlation between national average scores on these two scales was 0.65. The correlation coefficients within countries (accompanied by their respective standard errors) indicate that teachers who perceived greater availability of ICT at their schools also tended to perceive higher levels of teacher collaboration. The average correlation coefficient across countries was 0.36, ranging from 0.24 (in Finland) to 0.53 (in Moscow, Russian Federation), and the associations were statistically significant in all countries.

The highest teacher perceptions scale scores regarding the availability of ICT resources at school were recorded in Denmark, Kazakhstan, and Moscow (Russian Federation), while the lowest average was observed in North Rhine-Westphalia (Germany). For perceptions of teacher collaboration, we found the highest averages in Kazakhstan and Moscow (Russian Federation) and the lowest average again in the German benchmarking participant North Rhine-Westphalia.

Earlier, and in line with findings from the previous ICILS cycle in 2013 (Fraillon et al. 2014), we found evidence for an association between teachers' daily use of ICT for teaching and their views regarding this technology. In order to review the extent to which perceptions of ICT availability and collaboration were related to the frequency of teachers' use of ICT, we compared scale score averages between teachers who reported daily use of ICT for teaching with those teachers who reported less frequent use (Table 6.13). 


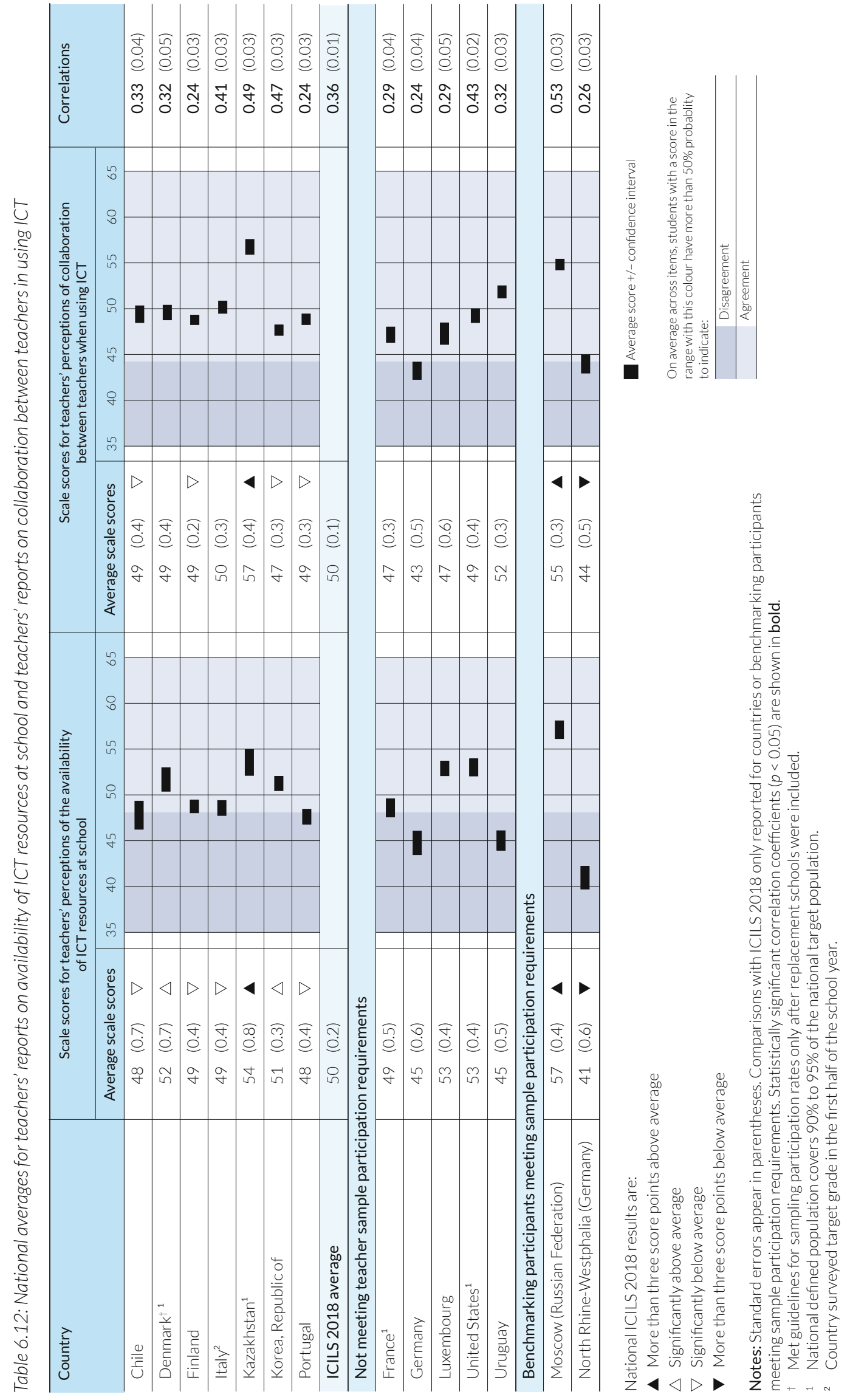




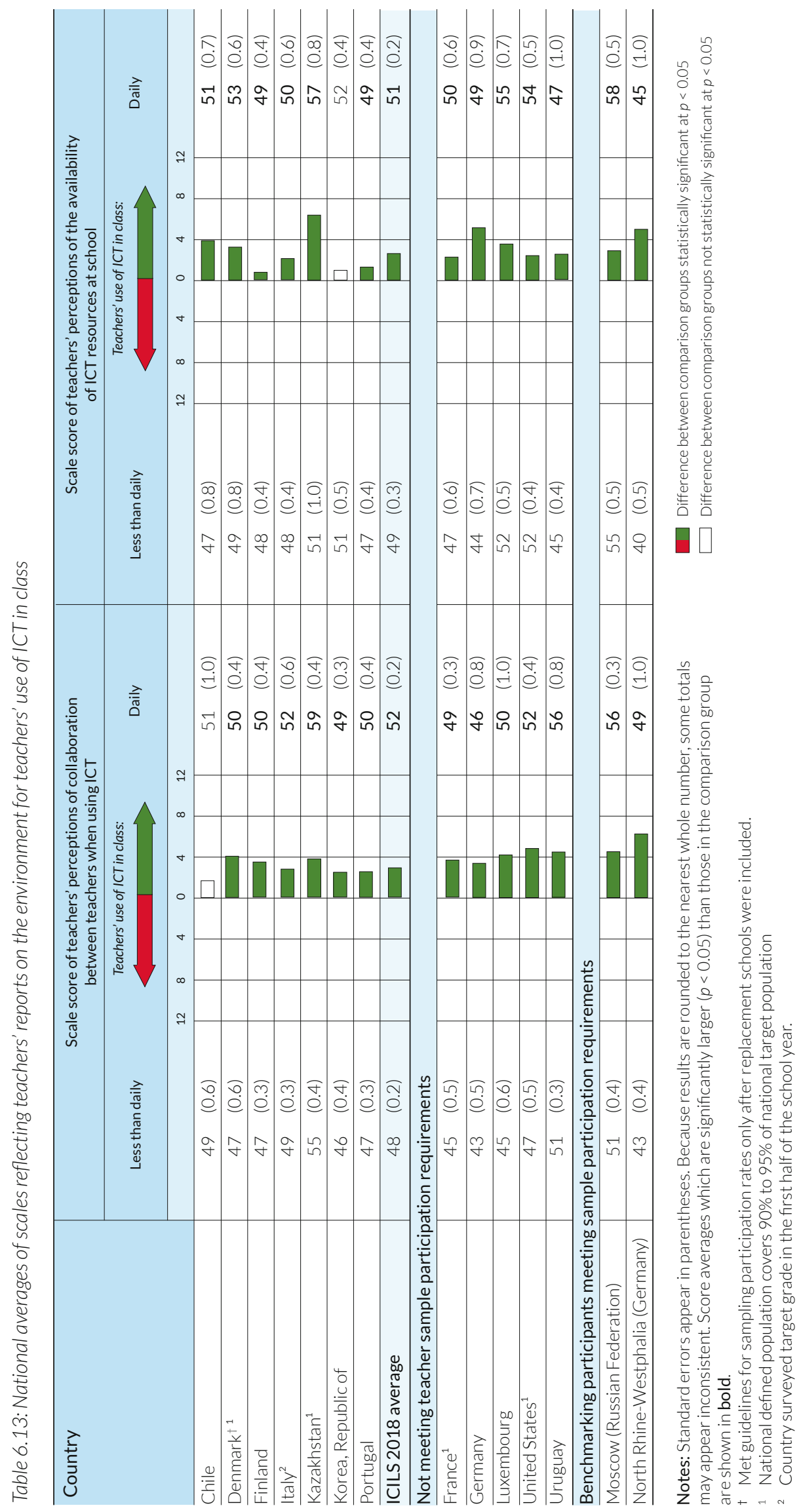


The results demonstrate that across participating countries teachers who used ICT on a daily basis for teaching tended to have more positive views of the availability of ICT resources as well as of the extent of collaboration between teachers. In most countries the scale score differences were statistically significant, except for in Chile regarding the availability of ICT resources at school and in Korea regarding teacher collaboration when using ICT. Differences between the comparison groups were on average more than three score points for teachers' perceptions of ICT availability, with the largest difference recorded for North Rhine-Westphalia (Germany). Teachers who used ICT on a daily basis were also more likely to perceive higher levels of teacher collaboration regarding ICT: the average score point difference was almost three points, with the largest differences (above five points) recorded in Kazakhstan and North Rhine-Westphalia (Germany).

These data suggest that there were differences in the perceptions of ICT resources and teacher collaboration depending on how often teachers use ICT in class. Readers should note that these bivariate associations do not indicate any clear causality. While it is possible that teachers less concerned with (and perhaps less knowledgeable of) ICT use tend to perceive ICT environments as less favorable, it is also possible that the association is rather explained by the enablement of teachers' use of ICT through higher levels of resources and collaboration with colleagues.

\section{Perceptions of professional development for pedagogical ICT use}

The development of teacher expertise in ICT-related teaching and learning has been identified as an important variable in enabling teachers' use of ICT and the teaching and learning of ICT-related skills (Charalambos and Glass 2007; Law et al. 2008; Lawrence and Tar 2018; Scherer and Siddiq 2015). The ICILS 2018 school principal questionnaire asked about schools' expectations and requirements of teachers' acquisition of knowledge with regard to a wider range of ICT-based activities. Principals rated the expectation of teachers' acquisition of knowledge to undertake a range of ICT-based activities as "expected and required," "expected but not required," or "not expected." The results are presented as the percentages of students who study at schools where principals reported each of the professional development activities as both expected and required.

The results show very large differences across participating countries (Table 6.14). While in Kazakhstan and Moscow (Russian Federation) for all activities, and in Denmark for most activities, there were majorities of students who studied at schools where these were required, in most countries only relatively few students were enrolled at institutions where teachers were expected and required to have the corresponding knowledge for these ICT-related activities. For the requirement of integrating ICT into teaching and learning we found the highest proportions of students at schools where this was the case (52\% on average). Few students across countries were enrolled at schools where teachers were expected and required to acquire knowledge about the use of e-portfolios for assessment (17\%) or about the use of ICT for developing authentic assignments for students (18\%).

The ICILS 2018 teacher questionnaire included a question regarding the respondents' participation in a range of different professional learning activities related to ICT over the past two years, where respondents were asked to state whether they had done each of these "not at all," "once only," or "more than once." The results are presented as percentages of teachers who reported having participated at least once in these activities (i.e., combining percentages in the last two response categories).

On average across countries, more than half of the surveyed teachers reported having participated at least once over the past two years in a course on ICT applications (51\%), observed other teachers using ICT in teaching (59\%), and shared digital teaching and learning resources in a digital workspace with others (57\%) (Table 6.15). While half of the teachers reported having received training in subject-specific digital teaching and learning resources, less than half of 


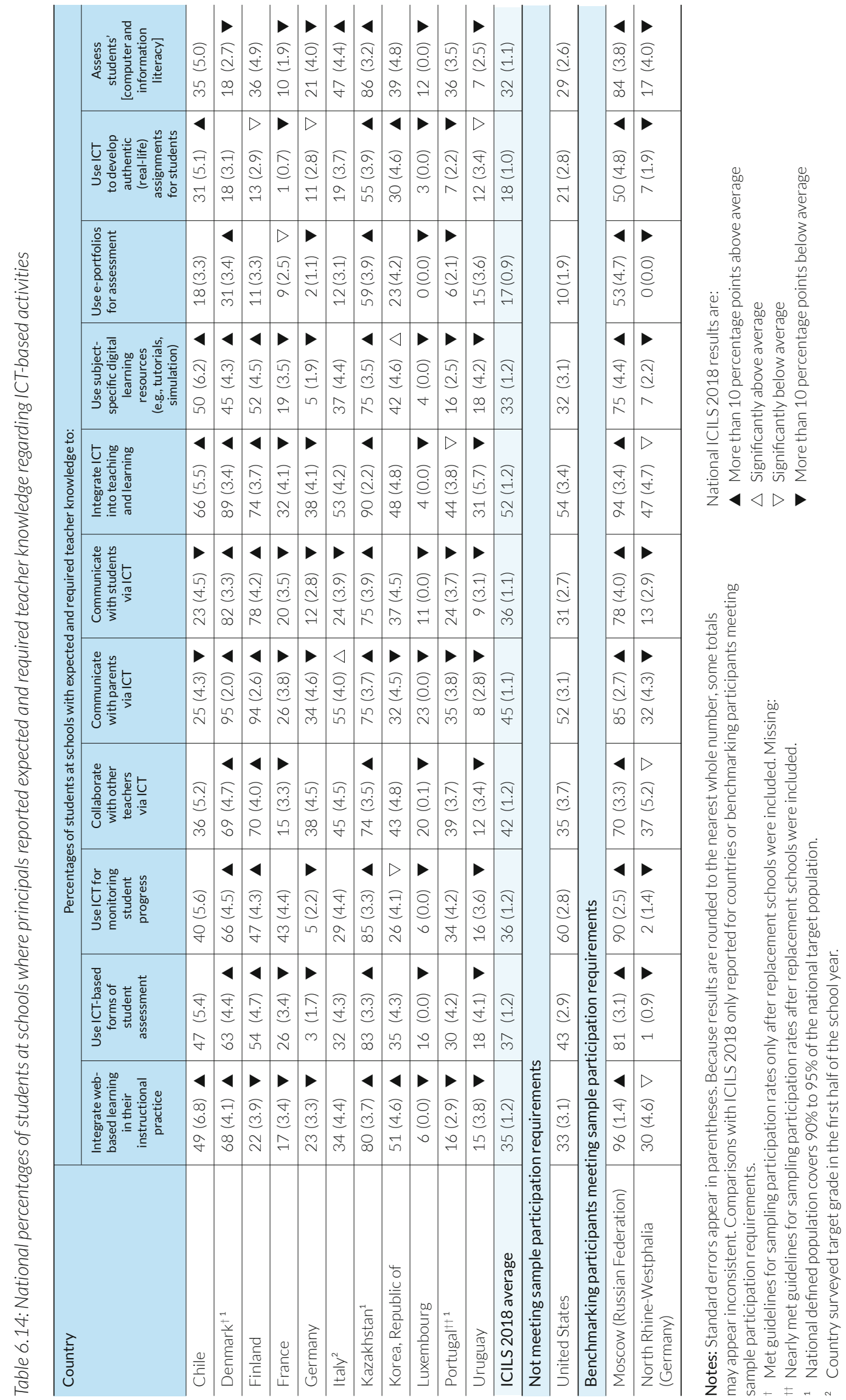




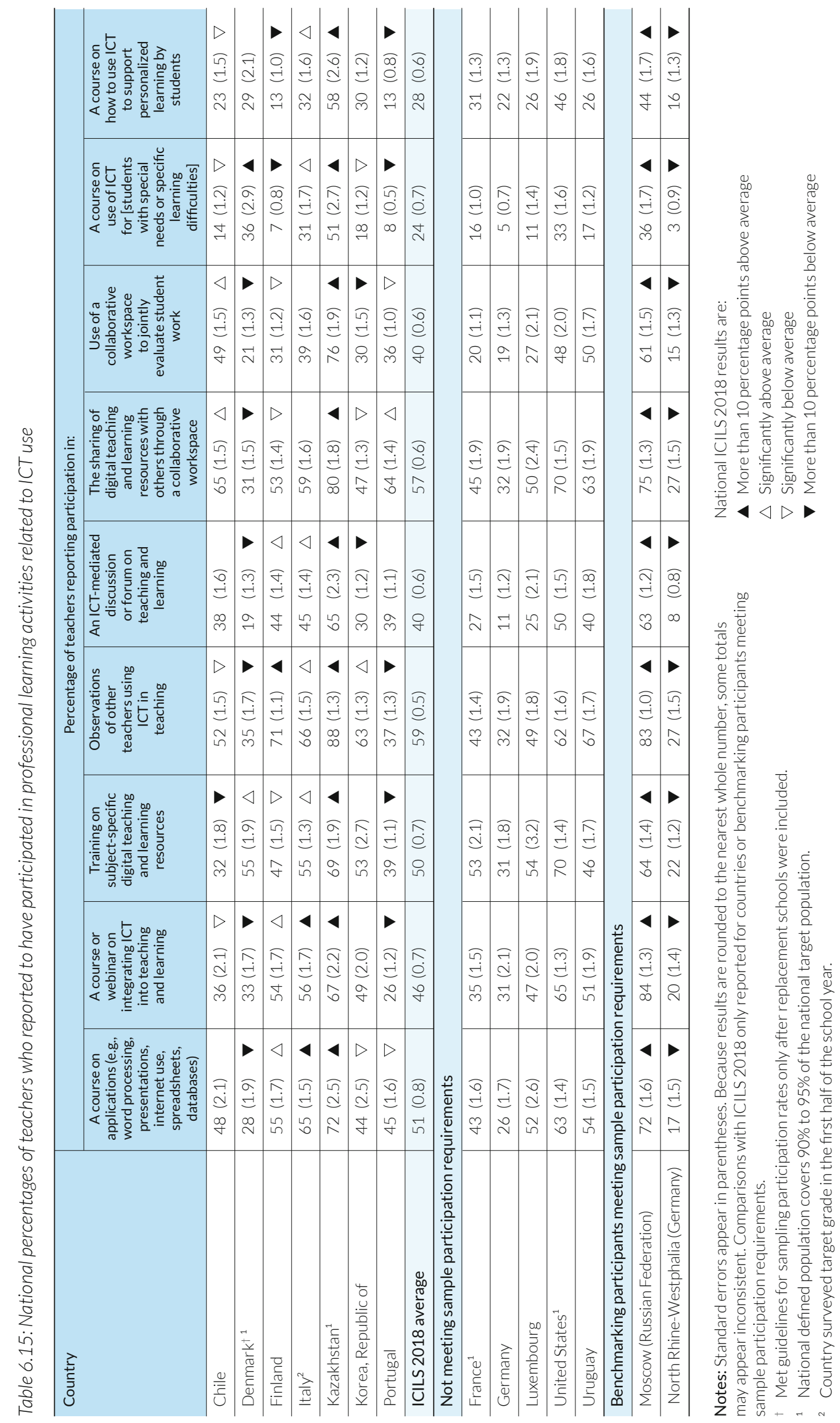


them reported participation in courses or webinars on integrating ICT into teaching and learning (46\%), in ICT-mediated discussions or fora on teaching and learning (40\%), or in collaborative workspaces to jointly evaluate student work. Less than a third of teachers on average across countries reported participation in courses on the use of ICT for students with special needs or specific learning difficulties (24\%) and in courses on how to use ICT to support personalized learning of students (28\%).

There were notable variations across participating countries and benchmarking entities. While relatively high percentages among teachers in Italy, Kazakhstan, and Moscow (Russian Federation) tended to report participation in these activities, these proportions were notably smaller in Denmark, Portugal, and, in particular, in North Rhine-Westphalia (Germany). It is noteworthy that some of the countries where teachers reported low participation in professional learning activities, there were also reports of high levels of ICT use and self-efficacy, while some of those with high levels of participation were characterized by relatively lower levels of ICT use and self-efficacy. However, this finding is consistent with an interpretation that suggests that in countries with low levels of ICT use more professional learning is offered so as to support and encourage further ICT use. In countries where there are already high levels of ICT use there may be less perceived need to provide professional learning to support its use.

\section{Teacher emphasis on learning CIL and CT}

\section{Teachers' emphasis on developing CIL-related skills}

While teachers' self-efficacy, their perceptions of, and their attitudes toward the use of ICT have been highlighted as important factors influencing the implementation of digital learning at school (Lawrence and Tar 2018; Tondeur et al. 2017), it is also important to consider the extent to which teachers place emphasis on the teaching of digital skills during class (Siddiq et al. 2016). Results from ICILS 2013 showed that across participating countries there were relatively high levels of teachers who reported to emphasize CIL-related skills in their teaching, and that the extent of this emphasis was related to their sense of ICT self-efficacy, views of the use of ICT in class, and perceptions of teacher collaboration regarding ICT use at school (Fraillon et al. 2014).

To capture the emphasis on developing CIL/CT, ICILS 2018 asked teachers to answer a question with regard to the specific reference class at the target grade, which they had identified prior to the question (see introduction to this chapter).

Teachers were asked about the emphasis they gave in their reference class to developing nine different ICT-based capabilities in their students ("strong emphasis," "some emphasis," "little emphasis," or "no emphasis"):

(a) to access information efficiently (85\% on average across countries reported some or strong emphasis)

(b) to display information for a given audience/purpose (78\%)

(c) to evaluate the credibility of digital information (74\%)

(d) to share digital information with others (71\%)

(e) to use computer software to construct digital work products (e.g., presentations, documents, images, and diagrams) (76\%)

(f) to provide digital feedback on the work of others (such as classmates) (49\%)

(g) to explore a range of digital resources when searching for information (75\%)

(h) to provide references for digital information sources (67\%)

(i) to understand the consequences of making information publicly available online (67\%). 
Across countries most teachers reported some or strong emphasis in their teaching on these capabilities. All nine items were used to derive an IRT scale reflecting teachers' emphasis on developing ICT-based capabilities in class. The scale has satisfactory reliabilities across countries (Cronbach's alpha $=0.90$ ) and items were scored so that higher scale scores indicated stronger emphasis on the development of ICT-related capabilities (see the corresponding item map in Figure F.22 in Appendix F).

The highest levels of teacher emphasis were recorded in Italy and Kazakhstan, while teachers in Finland and, in particular, in North Rhine-Westphalia (Germany) reported lower levels of emphasis (Table 6.16). When comparing teacher emphasis across different subject areas, ${ }^{24}$ not surprisingly the highest average scores (across countries) were reported by teachers referring to ICT-related classes (i.e., subjects that focus on teaching ICT-related skills). We also observed relatively high scores with regard to test language and human sciences classes. The lowest scores of teacher emphasis were observed for mathematics and classes related to other subjects such as vocational, moral/ethics, and physical education. These findings are broadly consistent with those from ICILS 2013 (Fraillon et al. 2014).

To assess the associations of teacher emphasis with other ICT-related perceptions, we estimated linear multiple regression models to explain variance in teacher emphasis on teaching ICT-based skills. We used the following scales as predictors in this model: teachers' self-efficacy, teachers' positive views of using ICT for teaching and learning, teachers' reports on collaboration between teachers when using ICT, and teachers' reports on the availability of ICT resources at school. Furthermore, we included teachers' reported experience with the use of ICT during lessons as an additional predictor variable.

All predictor variables were nationally standardized to having national average scores of zero and standard deviations of one. Therefore, the unstandardized regression coefficients (Table 6.17) indicate changes in teacher emphasis scores corresponding to an increase in one national standard deviation in each of the predictor variables after controlling for the effects of all other variables in the model. For teachers' experience with pedagogical use of ICT, we coded the responses so that regression coefficients indicate the change in scale scores with (approximately) one year of further experience. ${ }^{25}$

Both teachers' ICT self-efficacy and teachers' reports on ICT-related collaboration between teachers were statistically significant and consistent predictors of teacher emphasis in developing CIL in all countries. With one national standard deviation on the ICT self-efficacy scale, there was (on average across participating countries) an associated increase of over two score points in teacher emphasis in developing CIL (equivalent to approximately one fifth of a standard deviation). An increase of one national standard deviation in the teacher collaboration scale was (on average) associated with more than two score points increase.

Teachers' positive views of the use of ICT for teaching and learning were also positively and significantly associated with their emphasis on students' learning of ICT in all countries; on average, one national standard deviation was associated with an increase of almost two score points. The scale scores reflecting teachers' reports of the availability of ICT resources at school were not consistently associated with teacher emphasis on developing CIL; we found statistically significant coefficients only in Chile and Kazakhstan. Teachers' experience with the use of ICT during lessons was consistently positively associated with their emphasis on learning CIL-related skills. On average across countries, one more year of experience was approximately associated with an increase of about one score point.

24 In some countries, the number of teachers in subject-area subgroups were too small (below 30) to report estimates.

25 The response categories were coded as follows: "never" = 0, "less than two years" = 1, "between two and five years" $=3$, and "more than five years" $=5$. 


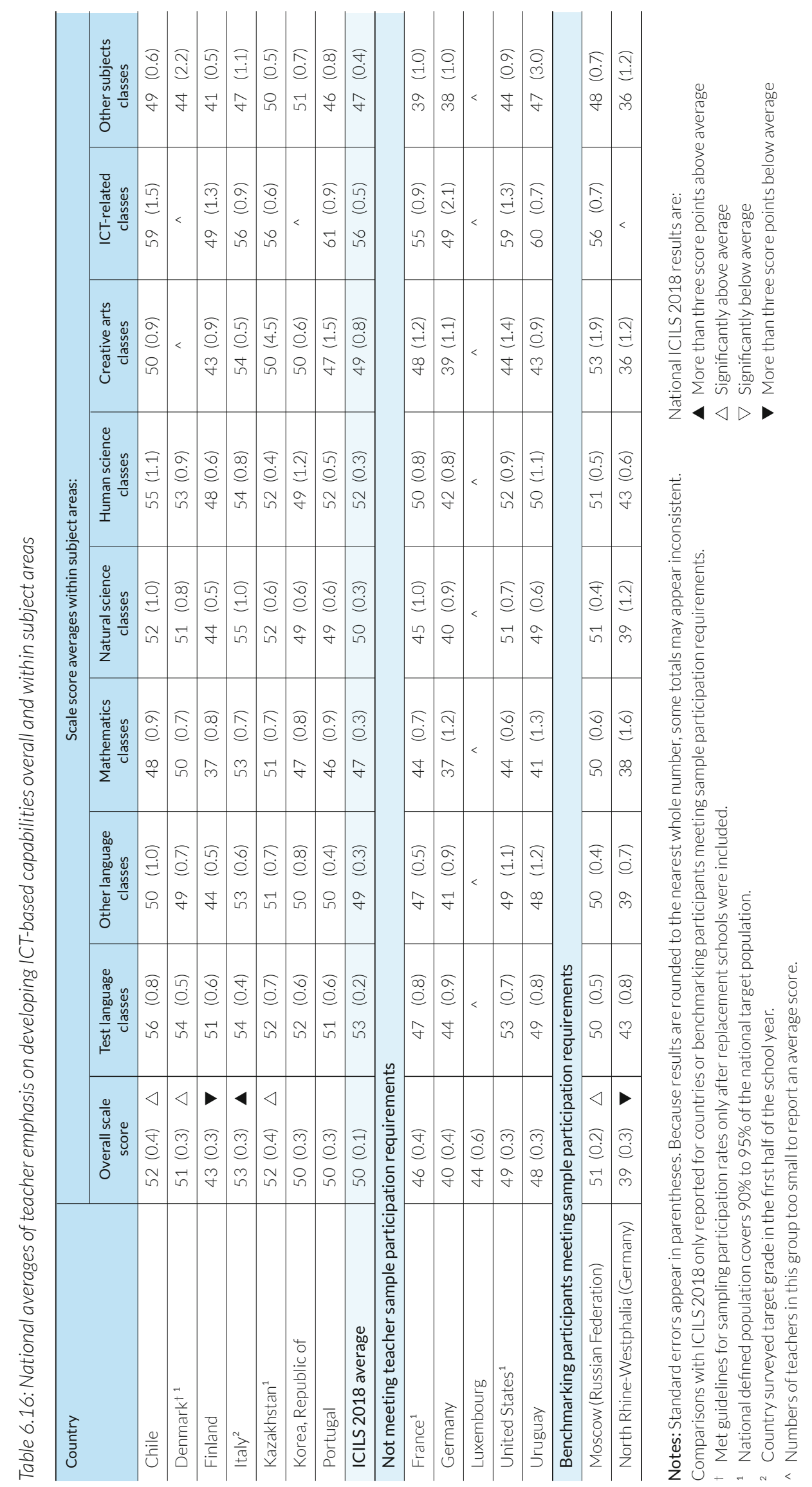




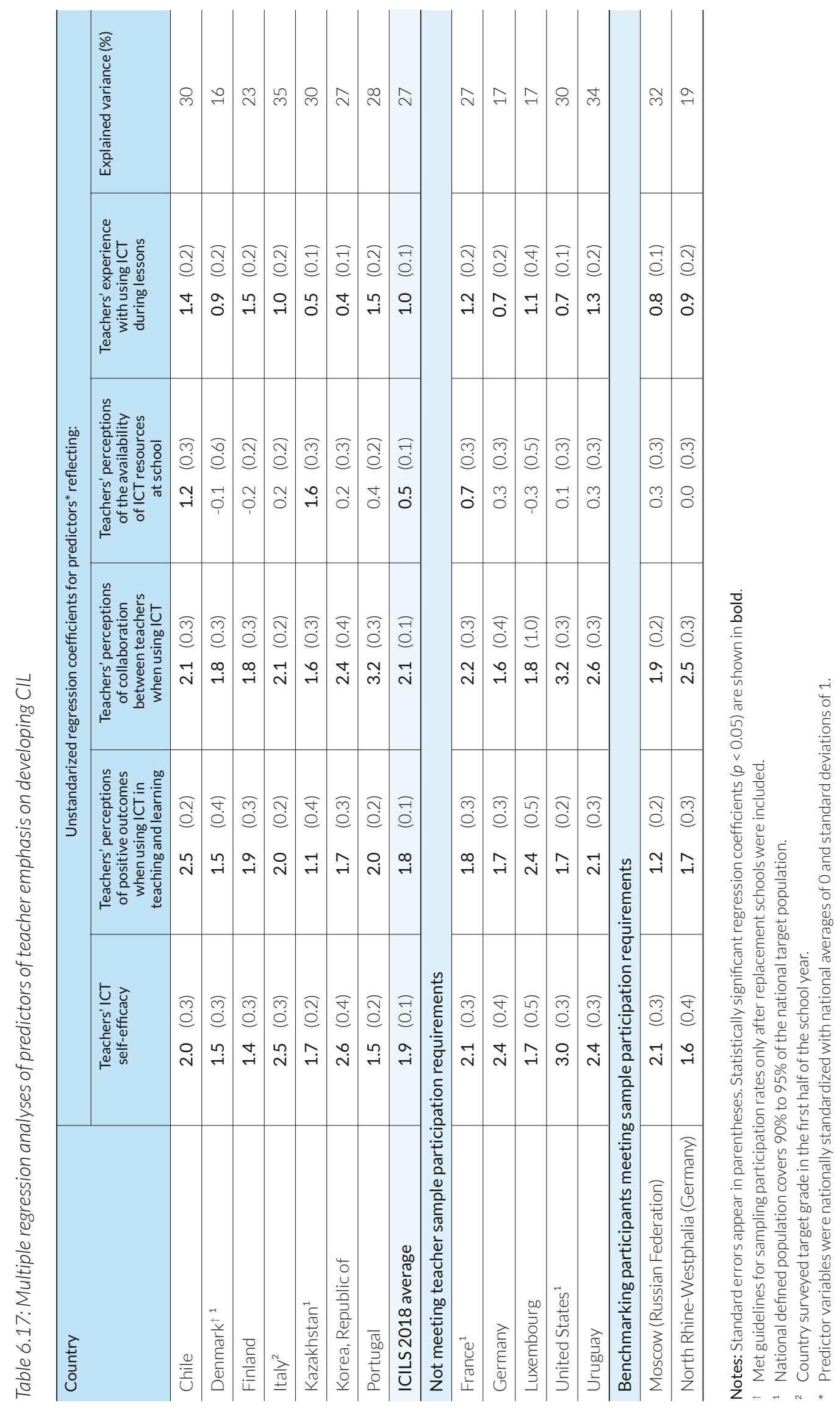


On average across participating countries, the regression model explained 27 percent of the variance in teachers' emphasis scores, ranging from 16 percent in Denmark to 35 percent in Italy. However, readers should be cautious about drawing any conclusions about causality from these analyses, as the cross-sectional design does not allow any causal interpretation. For example, it is possible that perceptions of teacher collaborations are also influenced by the teachers' own emphasis on teaching ICT-related skills, which leads to the need for more communication on how to achieve this.

\section{Teachers' emphasis on developing CT-related skills}

In recognition of the optional assessment of CT as part of ICILS 2018, the teacher questionnaire also included a question about how much emphasis teachers placed on teaching the following CT-related skills ("strong emphasis," "some emphasis," "little emphasis," or "no emphasis"):

(a) to display information in different ways (on average across countries $84 \%$ placed some or strong emphasis on this skill)

(b) to break a complex process into smaller parts (77\%)

(c) to understand diagrams that describe or show real-world problems (65\%)

(d) to plan tasks by setting out the steps needed to complete them (76\%)

(e) to use tools making diagrams that help solve problems (48\%)

(f) to use simulations to help understand or solve real-world problems (48\%)

(g) to make flow diagrams to show the different parts of a process (36\%)

(h) to record and evaluate data to understand and solve a problem (62\%)

(i) to use real-world data to review and revise solutions to problems (64\%).

All nine items were used to derive an IRT scale reflecting teachers' emphasis on teaching CTrelated skills in class. The scale has satisfactory reliabilities across countries (Cronbach's alpha $=0.90$ ) and items were scored so that higher scale scores indicated stronger emphasis on the teaching of CT-related tasks (see Figure F.23 in Appendix F, for the corresponding item map, which illustrates how scale scores are related to expected item responses).

The highest average scores for teacher emphasis on teaching CT-related skills were observed in Italy, Kazakhstan, and Moscow (Russian Federation), while we observed notably lower scale scores in Finland and North Rhine-Westphalia (Germany) (Table 6.18). When comparing teacher emphasis on the teaching of CT-related skills across subject areas, the highest scale scores were recorded for ICT-related classes, followed by mathematics and natural sciences, while the lowest scale scores were found for other language classes and other subjects' classes.

We also regressed scale scores reflecting teacher emphasis on teaching CT-related tasks on (nationally standardized) scale scores reflecting teachers' ICT self-efficacy, positive views on using ICT in teaching, perceptions of collaboration with other teachers for using ICT in teaching, views of the availability of ICT resources at school, and teachers' experience with using ICT during lessons (Table 6.19). The results show broadly similar results to those we observed for teacher emphasis on CIL-related skills.

Teachers' perceptions of collaboration with colleagues regarding the use of ICT for teaching were consistently positive and significantly related to teacher emphasis on CT-related skills. On average, an increase in one national standard deviation in the scale reflecting perceptions of teacher collaboration when using ICT was associated with an increase of over two scale score points in teacher emphasis on the teaching of CT-related tasks. Teachers' ICT self-efficacy was also consistently and significantly related to teacher emphasis on teaching CT-related skills (an increase of one national standard deviation corresponded to an increase of more than one score point in teacher emphasis) and teachers' positive views of ICT use in teaching were also a consistent and significant predictor (with an average effect of 1.1 scale score points). 


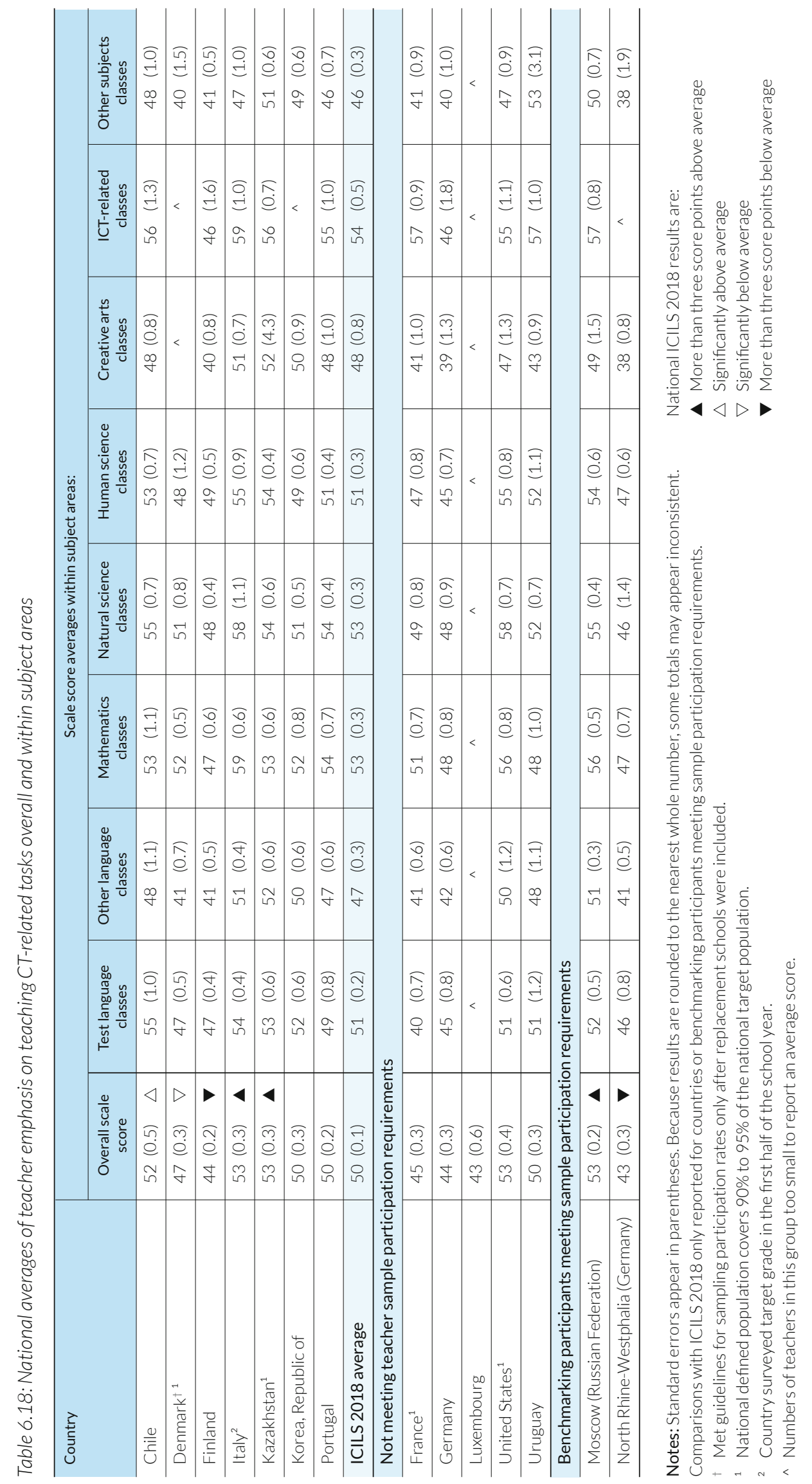




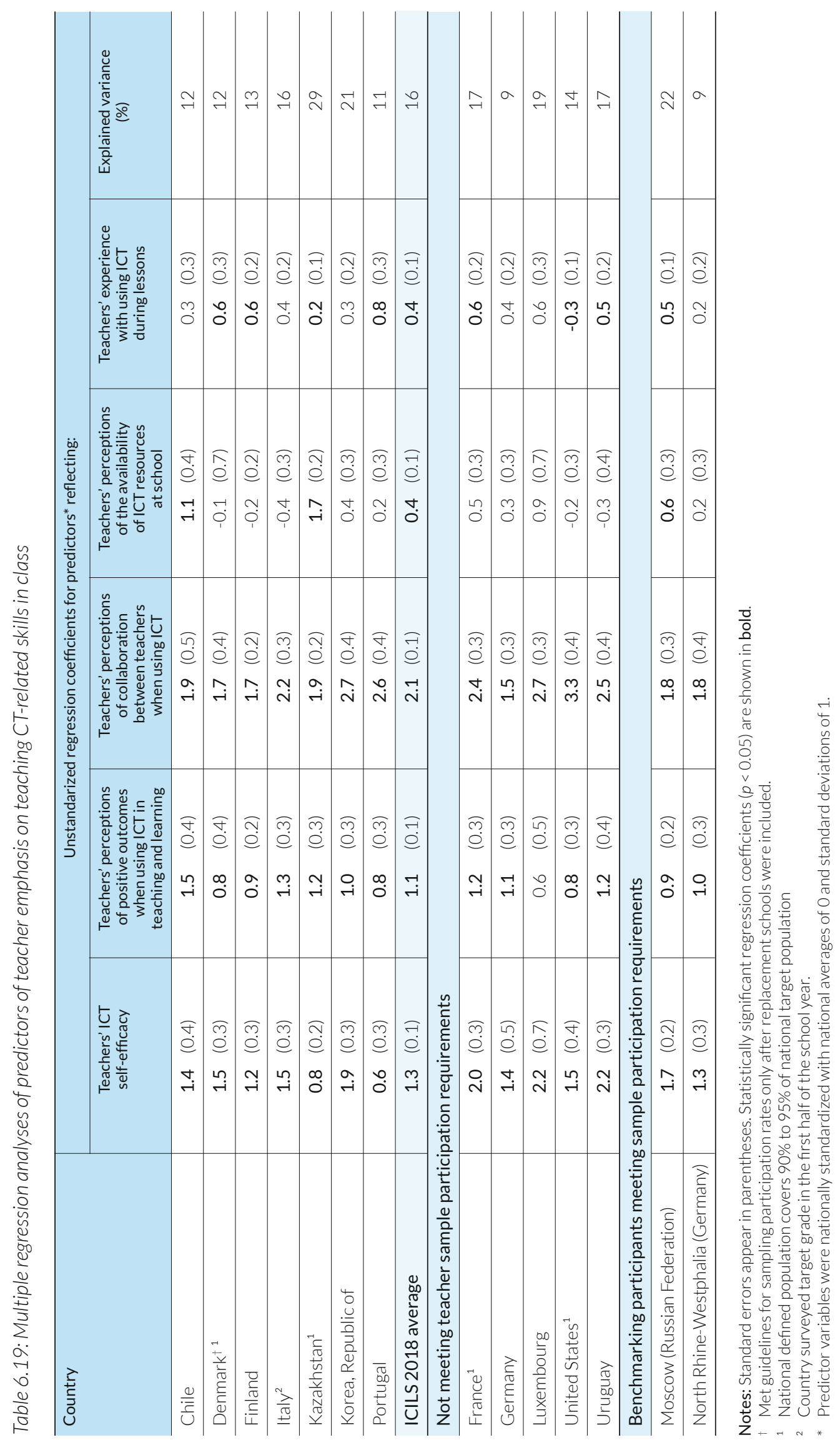


Teacher reports on the availability of ICT resources at school were positive predictors only in Chile and Kazakhstan, a result that is similar to the multiple regression results for teacher emphasis on CIL-related skills. Teachers' experience with the pedagogical use of ICT was a less consistent predictor in this model. We found significant effects only in about half the participating countries and, on average, approximately one year of further experience was associated with about half a score point of emphasis on the learning of CT-related skills.

The regression model explained 16 percent of the variance in scale scores reflecting teacher emphasis on CT-related skills, ranging from nine percent in North Rhine-Westphalia (Germany) and 11 percent in Portugal to 29 percent in Kazakhstan. When interpreting these results, it is important to remember the caveats with regard to drawing causal conclusions based on crosssectional data made earlier in this chapter.

\section{Teachers' use of ICT for teaching and learning}

Results from previous cross-national studies such as SITES 2006 (Law et al. 2008) and ICILS 2013 (Fraillon et al. 2014) have shown that schools and classrooms vary in the extent to which educators use ICT in teaching. Even though e-learning technologies are widely perceived as bringing transformative effects to classrooms (see Aparicio et al. 2016; Burbules 2007), their implementation has been relatively limited (see Cuban 2001; Stošic 2015; Vrasidas 2015) and the effectiveness of ICT for promoting learning appears to depend on teachers' actual practices and their ability of integrate digital technologies into teaching practice (Comi et al. 2017). The ICILS 2013 results showed that, while majorities of teachers reported using ICT for teaching, they used it more frequently for relatively simple tasks than more complex tasks (see Fraillon et al. 2014).

\section{Teachers' use of ICT tools in class}

ICILS 2018 asked teachers to rate the frequency ("never," "in some lessons," "in most lessons," or "in every, or almost every lesson") with which they used 16 different tools when teaching the nominated reference class during the current school year. The tools can be subdivided into general utility ICT tools and (more specific) digital learning tools.

There were differences in the percentages of teachers who reported using various general utility ICT tools "in most lessons" or "in every, or almost every lesson" (i.e., combining the two highest frequency categories) (Table 6.20). On average across countries, the most frequently used general utility tools were those for word processing (43\%) and presentations (43\%), followed by using computer-based information for capture and editing (36\%), and digital contents linked with textbooks (32\%). Meanwhile, spreadsheets (17\%), video and photo software for capture and editing (15\%), and communication software (22\%) were less frequently used by teachers. There were also some notable differences across countries: while teachers in Kazakhstan, Korea, and Moscow (Russian Federation) tended to report higher levels of use across the different tools, the lowest levels of use were recorded in Italy and North Rhine-Westphalia (Germany).

When reviewing the percentages of teachers who reported using digital learning tools in most lessons, or in almost every or every lesson (Table 6.21), we found generally lower proportions of teachers with frequent use than for general utility software. The most frequently used learning tools were learning management systems, which, on average across countries, 28 percent of teachers reported as used in most lessons or more frequently. In this context it is worth noting that across participating countries, teachers expressed less confidence in using these tools compared to other forms of ICT use (see Table 6.2). The proportions of teachers that were using this type of tool varied considerably, from only five percent or less in Chile, Italy, Portugal, and North Rhine-Westphalia (Germany), to more than half of the teachers in Finland (53\%) and Kazakhstan (73\%). 


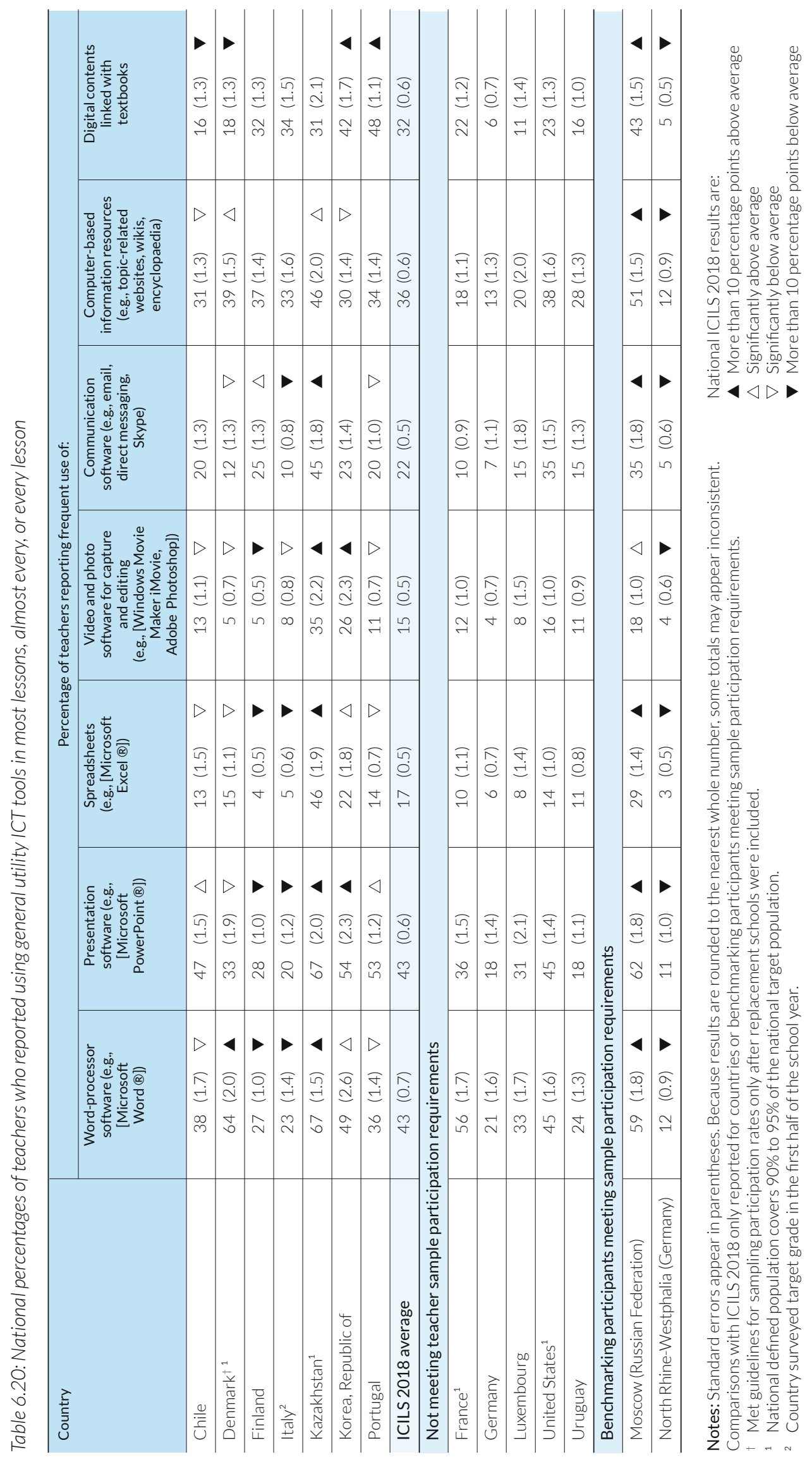




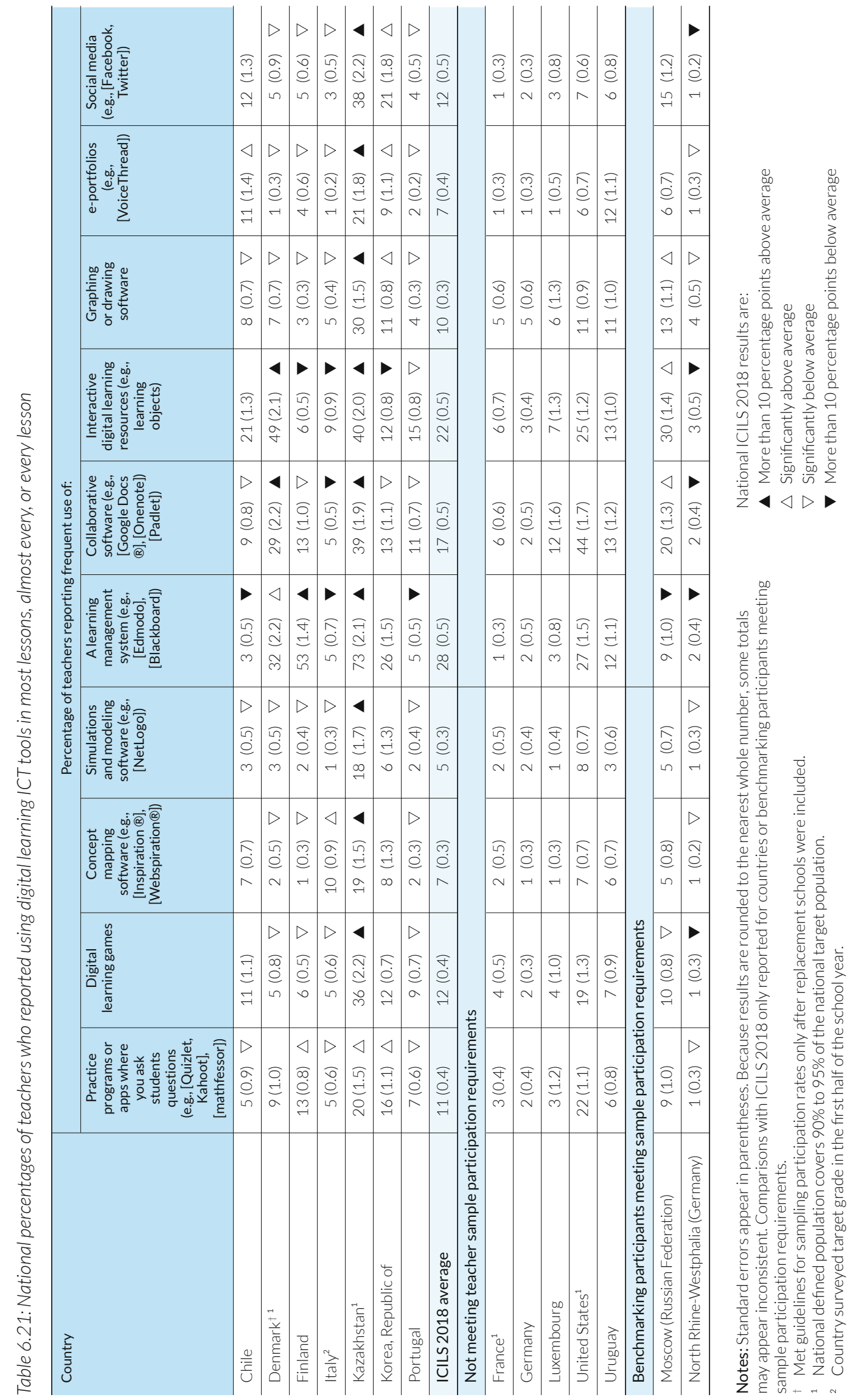


Interactive learning resources were more frequently used (22\%) than most other digital learning tools. In addition, there were notable between-country variations in the proportions of teachers who reported more frequent use of interactive learning resources, ranging from less than 10 percent in Chile, Italy, and North Rhine-Westphalia (Germany), to almost half of the teachers in Denmark. Frequent use of collaborative software was reported by 17 percent of the teachers on average, again with considerable variation in the proportions across countries.

More frequent use of practice programs or apps to ask students questions, digital learning games, graphing or drawing software, and social media were, on average, reported by about 10 percent of the surveyed teachers, again with some variations across countries. The least commonly used digital learning tools (reported by on average $<10 \%$ of teachers) were concept mapping software, simulation and modeling software, and e-portfolios.

\section{Teachers' use of ICT for class activities and teaching practices}

ICILS 2018 was also interested in finding out about the extent to which ICT was used for different types of learning activities in class. Teachers were asked to provide information about whether their students engaged in a set range of activities, and how often they used ICT as part of these activities ("they do not engage in this activity," "they never use ICT in this activity," "they sometimes use ICT in this activity," "they often use ICT in this activity," or "they always use ICT in this activity"). We present the results as percentages of teachers who reported that their students often or always used ICT; data from teachers who indicated that their students had not engaged in each of these activities were not included in these percentages (Table 6.22).

On average across participating countries, half or almost half of the teachers reported that students frequently used ICT when collecting data for a project (50\%), creating visual products or videos (47\%), working on extended projects of more than a week (46\%), and working on short assignments of less than a week's duration (46\%). More than a third of teachers (on average) also reported that students often or always used ICT when submitting completed work assessments (41\%), sharing products with other students (40\%), working individually on learning materials at their own pace (37\%), undertaking open-ended investigations or field work (35\%), and evaluating information resulting from a search (34\%). Less than a third of teachers reported frequent use of ICT by students when analyzing data (32\%), communicating on projects with other students in other schools (28\%), explaining and discussing ideas with other students (26\%), engaging in reflections on their learning experiences (22\%), and planning a sequence of learning activities for themselves (22\%).

We also observed notable differences across countries. While relatively low proportions of teachers in Finland, Portugal, and North Rhine-Westphalia (Germany) reported frequent use of ICT for these different learning activities, they tended to be much higher in Denmark, Kazakhstan, and Moscow (Russian Federation). When reviewing these results, readers should consider that these percentages are based on only those teachers who reported that their students engaged in each of the learning activities, and that there were substantial proportions of teachers who reported that these were not undertaken in their reference class (ranging from 10\% for work on extended projects, to $31 \%$ for reflections on learning experiences).

The ICILS 2018 teacher questionnaire also included a question regarding their use of teaching practices and the frequency of use of ICT when applying them ("I do not use this practice with the reference class," "I never use ICT with this practice," "I sometimes use ICT with this practice," "I often use ICT with this practice," or "I always use ICT with this practice"). Again, the results are presented as percentages of teachers who often or always used ICT based on all teachers who reported using each of these practices (teachers who did not use this practice with the reference class were excluded from the calculations). 


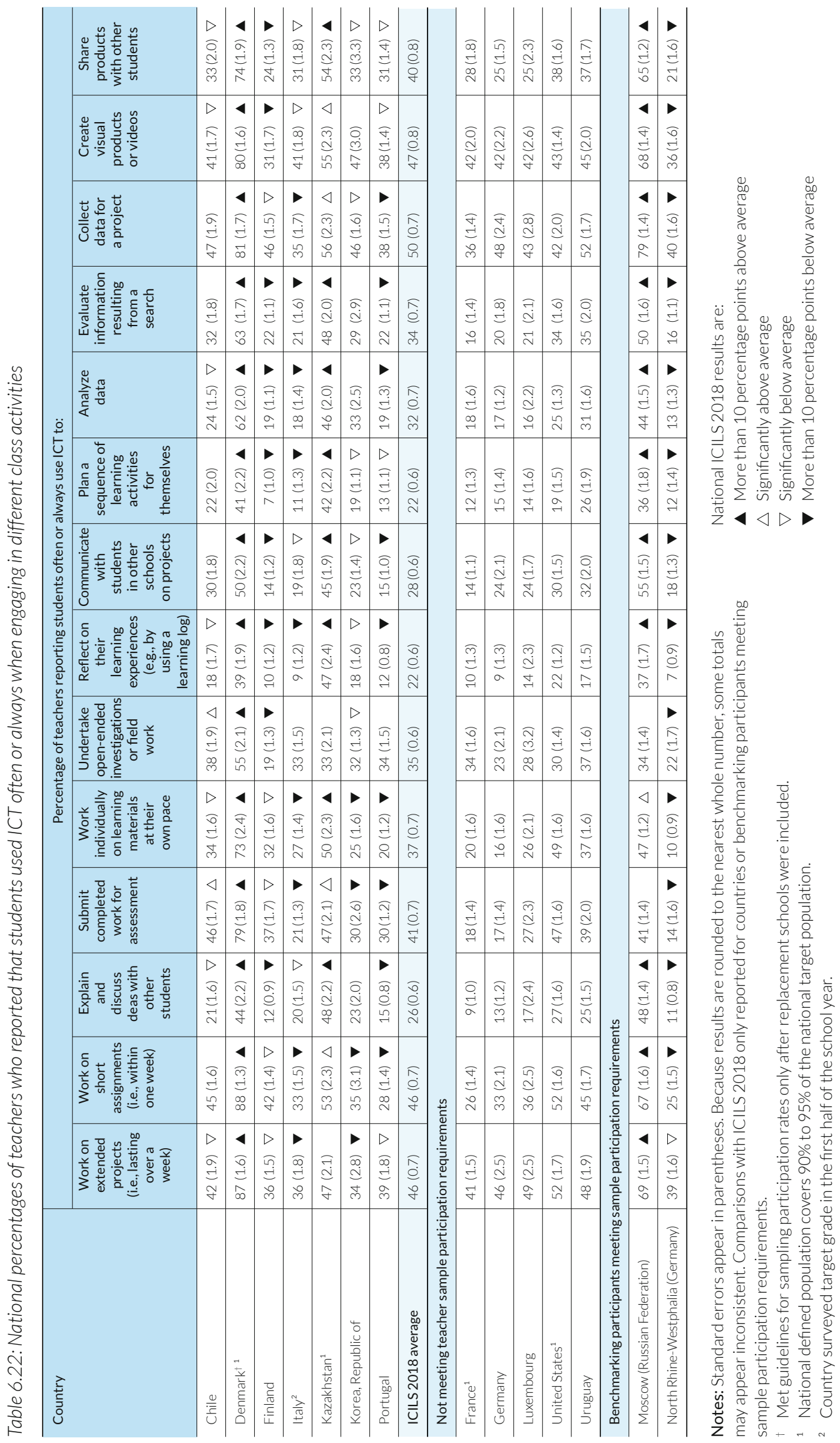




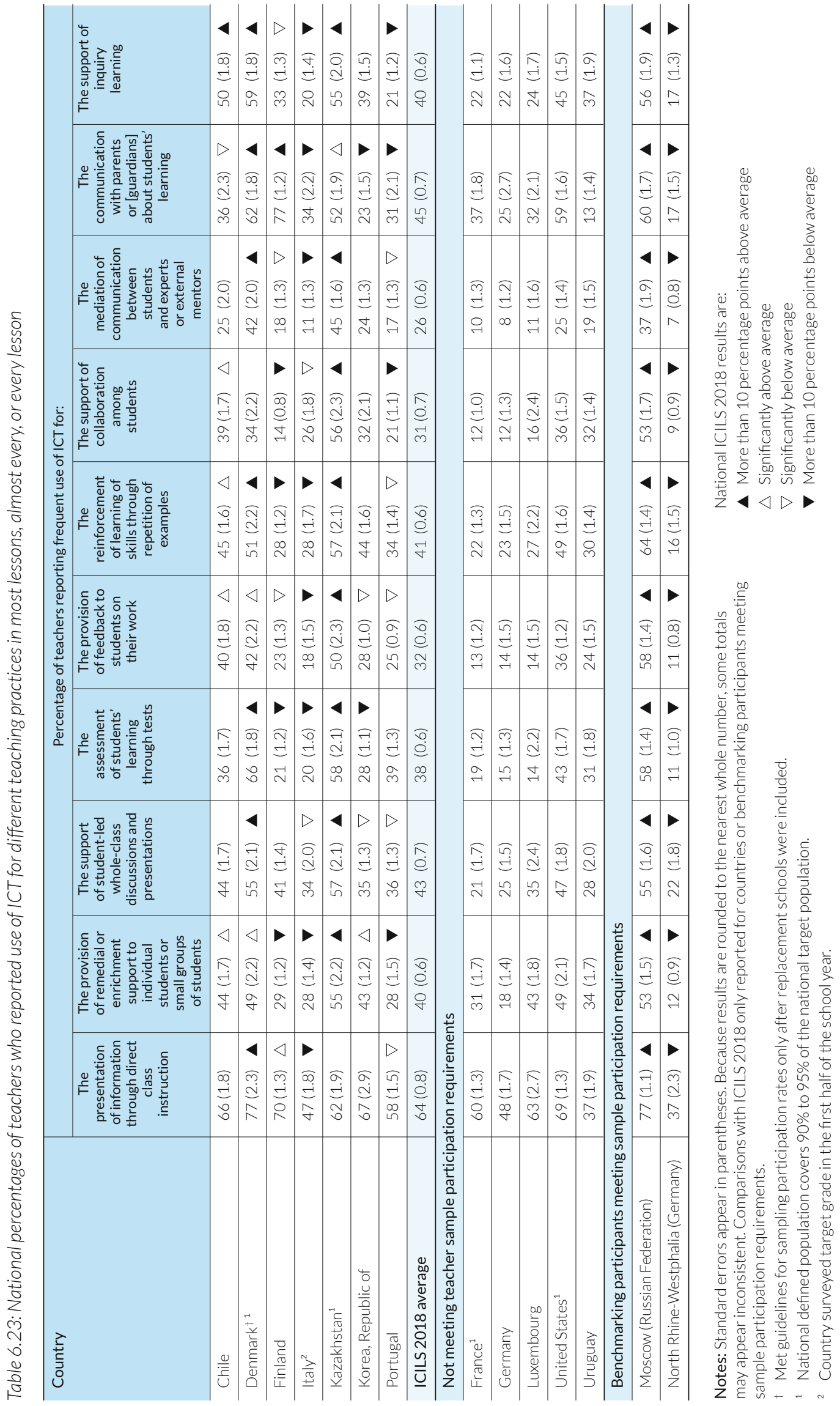


On average across ICILS 2018 countries, almost two-thirds of teachers who presented information through direct class instruction reported often or always using ICT (64\%) (Table 6.23). Between a third and a half of those teachers often or always made use of ICT when communicating with parents or guardians about students' learning (45\%), when supporting student-led whole-class group discussions and presentations (43\%), when providing remedial or enrichment support to individuals or groups of students (40\%), when supporting inquiry learning (40\%), and when assessing students' learning through tests (38\%). Less than a third of teachers reported more frequent use of ICT when providing feedback to students on their work (32\%), when supporting collaboration among students (31\%), and when mediating communication between students and experts or external mentors (26\%).

Again we observed considerable variation across countries. While teachers in Denmark, Kazakhstan, and Moscow (Russian Federation) reported relatively high frequencies of ICT use across the different teaching practices, frequent ICT use tended to be much lower in Italy and North Rhine-Westphalia (Germany). When interpreting these data it is important to note that the percentages were based only on teachers who reported applying these teaching practices; the proportions of teachers who did not use these practices in their reference class ranged (on average across countries) from six percent (for presenting information through direct instruction) to 33 percent (for mediating communication between students and experts or external mentors).

\section{References}

Aparicio, M., Bacao, F., \& Oliveira, T. (2016). An e-learning theoretical framework. Educational Technology \& Society, 19(1), 292-307.

Bandura, A. (1997). Self-efficacy: The exercise of control. New York, NY: W.H. Freeman.

Burbules, N. (2007). E-lessons learned. National Society for the Study of Education 2007 Yearbook, 106(2), 207-216.

Caspersen, J., \& Raaen, F.D. (2014). Novice teachers and how they cope. Teachers and Teaching: Theory and Practice, 20, 189-211.

Charalambos, V., \& Glass, G. (2007). Teacher professional development and ICT: Strategies and models. National Society for the Study of Education 2007 Yearbook, 106(2), 87-102.

Comi, S.L., Argentin, G., Gui, M., Origo, F., \& Pagani, L. (2017). Is it the way they use it? Teachers, ICT and student achievement. Economics of Education Review, 56, 24-39.

Cuban, L. (2001). Oversold and underused: Computers in the classroom. Cambridge, MA: Harvard University Press.

Drossel, K., Eickelmann, B., \& Gerick, J. (2017). Predictors of teachers' use of ICT in school -the relevance of school characteristics, teachers' attitudes and teacher collaboration. Education and Information Technologies, 22(2), 551-573. Retrieved from https://link.springer.com/article/10.1007\%2Fs10639-016-9476-y.

Eickelmann, B. (2011). Supportive and hindering factors to a sustainable implementation of ICT in schools. Journal for Educational Research Online, 3(1), 75-103.

Fraillon, J., Ainley, J., Schulz, W., Duckworth, D., \& Friedman, T. (2019). IEA International Computer and Information Literacy Study 2018 assessment framework. Cham, Switzerland: Springer. Retrieved from https:// www.springer.com/gp/book/9783030193881.

Fraillon, J., Ainley, J., Schulz, W., Friedman, T., \& Gebhardt, E. (2014). Preparing for life in a digital age: The IEA International Computer and Information Literacy Study international report. Cham, Switzerland: Springer. Retrieved from https://www.springer.com/gp/book/9783319142210.

Fraillon, J., Schulz, W., \& Ainley, J. (2013). International Computer and Information Literacy Study assessment framework. Amsterdam, The Netherlands: International Association for the Evaluation of Educational Achievement (IEA). Retrieved from https://www.iea.nl/publications/assessment-framework/internationalcomputer-and-information-literacy-study-2013.

Fraillon, J., Schulz, W., Friedman, T., \& Meyer, S. (Eds.). (2020). IEA International Computer and Information Literacy Study 2018 technical report. Amsterdam, The Netherlands: International Association for the Evaluation of Educational Achievement (IEA). Manuscript in preparation. 
Gerick, J., Eickelmann, B., \& Bos, W. (2017). School-level predictors for the use of ICT in schools and students' CIL in international comparison. Large-scale Assessments in Education, 5, 5. Retrieved from https:// doi.org/10.1186/s40536-017-0037-7.

Hatlevik, O.E. (2017). Examining the relationship between teacher's self-efficacy, their digital competence, strategies to evaluate information, and use of ICT at school. Scandinavian Journal of Educational Research, 61(5), 555-567.

Hatlevik, I., \& Hatlevik, O.E. (2018). Examining the relationship between teachers' ICT self-efficacy for educational purposes, collegial collaboration, lack of facilitation and the use of ICT in teaching practice. Frontiers in Psychology, 9, 935. Retrieved from https://doi.org/10.3389/fpsyg.2018.00935.

Kozma, R. (Ed.). (2003). Technology, innovation, and educatinal change: A global perspective. Eugene, OR: International Society for Technology in Education (ISTE).

Law, N., Pelgrum, W., \& Plomp, T. (2008). Pedagogy and ICT use in schools around the world: Findings from the IEA SITES 2006 study. (CERC studies in comparative education; No. 23.) Hong Kong SAR/The Netherlands: Comparative Education Research Centre, University of Hong Kong/Springer. Retrieved from https://www.springer.com/gp/book/9781402089275.

Lawrence, J.E., \& Tar, U.A. (2018). Factors that influence teachers' adoption and integration of ICT in teaching/learning process. Educational Media International, 55(1), 79-105.

Masters, G.N., \& Wright, B.D. (1997). The partial credit model. In W. J. van der Linden, \& R.K. Hambleton (Eds.), Handbook of modern item response theory (pp. 101-122). New York, NY: Springer. Retrieved from https://link.springer.com/chapter/10.1007/978-1-4757-2691-6_6.

Nikolopoulou, K., \& Gialamas, V. (2016). Barriers to ICT use in high schools: Greek teachers' perceptions. Journal of Computers in Education, 3(1), 59-75.

Rasch, G. (1960). Probabilistic models for some intelligence and attainment tests. Copenhagen, Denmark: Nielsen \& Lydiche.

Scherer, R., \& Siddiq, F. (2015). Revisiting teachers' computer self-efficacy: A differentiated view on gender differences. Computers in Human Behavior, 53, 48-57. Retrieved from https://doi.org/10.1016/j. chb.2015.06.038.

Siddiq, F., Scherer, R., \& Tondeur, J. (2016). Teachers' emphasis on developing students' digital information and communication skills (TEDDICS): A new construct in 21st century education. Computers \& Education, 92-93, 1-14. Retrieved from https://doi.org/10.1016/j.compedu.2015.10.006.

Stošić, L. (2015). The importance of educational technology in teaching. International Journal of Cognitive Research in Science, Engineering and Education (IJCRSEE), 3(1), 111-114. Retrieved from http://www.ijcrsee. com/index.php/ijcrsee/article/view/122.

Tamin, R., Bernard, R., Borokhovski, E., Abrami, P., \& Schmid, R. (2011). What forty years of research says about the impact of technology on learning: A second-order meta-analysis and validation study. Review of Educational Research, 81(1), 4-28. Retrieved from https://doi.org/10.3102\%2F0034654310393361.

Tondeur, J., van Braak, J., Ertmer, P.A., \& Ottenbreit-Leftwich, A. (2017). Understanding the relationship between teachers' pedagogical beliefs and technology use in education: a systematic review of qualitative evidence. Educational Technology Research and Development, 65(3), 555-575.

Vrasidas, C. (2015). The rhetoric of reform and teachers' use of ICT. British Journal of Educational Technology, 46, 370-380. Retrieved from https://onlinelibrary.wiley.com/doi/abs/10.1111/bjet.12149.

Wastiau, P., Blamire, R., Kearney, C., Quittre, V., Van de Gaer, E., \& Monseur, C. (2013). The use of ICT in education: a survey of schools in Europe. European Journal of Education, 48, 11-27. Retrieved from https://onlinelibrary.wiley.com/doi/abs/10.1111/ejed.12020.

Open Access This chapter is licensed under the terms of the Creative Commons Attribution-NonCommercial 4.0 International License (http://creativecommons.org/licenses/by-nc/4.0/), which permits any noncommercial use, sharing, adaptation, distribution and reproduction in any medium or format, as long as you give appropriate credit to the original author(s) and the source, provide a link to the Creative Commons license and indicate if changes were made.

The images or other third party material in this chapter are included in the chapter's Creative Commons license, unless indicated otherwise in a credit line to the material. If material is not included in the chapter's Creative Commons license and your intended use is not permitted by statutory regulation or exceeds the permitted use, you will need to obtain permission directly from the copyright holder. 